\title{
Inkjet-Printed Electronics on Paper for RF Identification (RFID) and Sensing
}

\author{
Sangkil Kim ${ }^{\mathbb{D}}$ \\ Pusan National University, Busan 46241, Korea; ksangkil3@pusan.ac.kr \\ Received: 22 July 2020; Accepted: 28 September 2020; Published: 4 October 2020
}

check for updates

\begin{abstract}
The newly developed research area of inkjet-printed radio frequency (RF) electronics on cellulose-based and synthetic paper substrates is introduced in this paper. This review paper presents the electrical properties of the paper substrates, the printed silver nanoparticle-based thin films, the dielectric layers, and the catalyst-based metallization process. Numerous inkjet-printed microwave passive/ative systems on paper, such as a printed radio frequency identification (RFID) tag, an RFID-enabled sensor utilizing carbon nanotubes (CNTs), a substrate-integrated waveguide (SIW), fully printed vias, an autonomous solar-powered beacon oscillator (active antenna), and artificial magnetic conductors (AMC), are discussed. The reported technology could potentially act as the foundation for true "green" low-cost scalable wireless topologies for autonomous Internet-of-Things (IoT), bio-monitoring, and "smart skin" applications.
\end{abstract}

Keywords: printed electronics; self-sustainable sensor platform; paper electronics; hybrid printed electronics; inkjet-printing technology

\section{Introduction}

Paper has been found to be available almost anywhere in a wide range of everyday applications due to its manufacturing maturity, low cost, and availability in various forms, depending on specific requirements and conditions. It is an extremely cost-efficient material that is typically 20-150 times lower than other polymeric materials, such as polyethylene terephtalate (PET) and polyimide (PI). It is also a highly flexible material, like polymers [1-3]. Paper is recyclable and free of phenolic ingredients, resulting in an environmentally friendly material. Paper substrates have attracted more and more attention as electronic substrates as the demand for inexpensive, flexible, and environmentally friendly technology has continued to grow [4-15].

The advantages of paper for electronics can be further enhanced in light of the large-area printed electronics fabrication process [16-21]. For example, an additive process such as inkjet printing technology does not produce any by-products, for example, strong acids (wet etching) or chips (milling machines) [22-29]. The printing process is also able to achieve relatively high printing resolutions below $25 \mu \mathrm{m}$ [30]. Among the many types of nano-particle inks made from metals such as copper $(\mathrm{Cu})$ [31] or gold $(\mathrm{Au})$ [32], silver nano-particle ink is widely utilized for printing conductive traces on paper because of its relatively low curing (sintering) temperature and high electrical conductivity. The advantages of paper substrate and printing technology makes it a strong candidate for the easy-to-scale implementation of next generation electronics for the Internet-of-Things (IoT), radio frequency identification (RFID)-based technologies, and printed passive/active electronics.

In Section 2, the electrical characteristics (dielectric constant and loss tangent) of two representative types of paper (cellulose-based and synthetic Teslin) are presented up to $8 \mathrm{GHz}$. The electrical properties of inkjet-printed silver nano-particle, electrolessly deposited copper thin film utilizing a palladium catalyst seed layer, as well as dielectric thin films (PVP and SU-8), are discussed. Section 3 introduces various proof-of-concept paper-based inkjet-printed radio frequency (RF) topologies. 


\section{Paper Substrates and Electronic Inks for Printing}

\subsection{Paper Substrates}

Paper substrates have many variations (e.g., cellulose-based and synthetic Teslin papers [33,34]). To realize inkjet-printed electronics on paper operating at RF and microwave frequencies, it is important to choose a proper substrate. The substrate should be compatible with the fabrication process. For instance, the inkjet-printed materials should show good adhesion on the substrate and withstand the sintering process without cracking, excessive shrinkage, warpage, and performance deterioration. Another important factor relates to the electrical model of the substrate, such as the relative permittivity $\left(\varepsilon_{r}\right)$ and dielectric loss tangent $(\tan \delta)$, over a wide range of frequencies, temperatures, and humidities. For inkjet-printed electronics on paper, it is critical to choose a proper paper, which is compatible with the overall manufacturing process and design requirements. In this section, two types of commonly used paper substrates are characterized: Cellulose-based photo-paper and Teslin. These two papers are widely adopted in everyday life and are compatible with most printing processes, such as inkjet, laser, and screen-printing.

\subsubsection{Cellulose-Based Photo-Paper}

Paper fabrication is a well-known and traditional process. A paper machine makes a paper web from cellulose-based pulps or fibers. Pressing and drying processes utilizing air or heat remove the water in the paper web mechanically. Additives, such as chalk or china clay, improve the quality and durability of paper. However, the bare cellulose-based paper is inappropriate for printing the nano-particle-based inks because of its rough surface and ink penetration through the paper substrate.

Paper has many advantages as a substrate for active/passive electronics, such as antennas, sensors, and RFIDs. It is not only a flexible, renewable, and biocompatible material, but is also able to withstand harsh environments, such as humid environments. The electrical properties of a widely used $0.25 \mathrm{~mm}$ thick cellulose-based polymer-coated photo-paper [35] have been thoroughly studied in [33]. The relative dielectric constant $\left(\varepsilon_{r}\right)$ and loss tangent ( $\left.\tan \delta\right)$ are presented in Figure 1a,b (black lines) for the 1-8 GHz frequency band. Those electrical parameters were extracted by both T-resonator [36] and ring resonator methods [37]. Its $\varepsilon_{r}$ is about 2.9-3.4 and the tan $\delta$ is about $5.3 \times 10^{-2}-6.2 \times 10^{-2}$. The relative permittivity of the paper $\left(\varepsilon_{r}=3.4\right)$ is quite similar to other commonly used RF substrates, such as liquid crystal polymer (LCP) $\left(\varepsilon_{r}=2.9\right.$, $\left.\tan \delta=2.5 \times 10^{-3}\right)$, polyimide $\left(\varepsilon_{r}=3.5, \tan \delta=2.6 \times 10^{-3}\right)$, and flame retardant 4 (FR4) $\left(\varepsilon_{r}=4.4, \tan \delta=1.8 \times 10^{-2}\right)$. The tan $\delta$ of the cellulose-based paper $\left(\tan \delta=5.3 \times 10^{-2}\right)$ is significantly higher than other materials because of its fiber-based organic composition. However, such a high value of the paper's loss tangent is not a critical factor for certain designs, such as low-quality factor $(Q$-factor $<5)$ designs [38-41]. This is because the interaction of the electromagnetic field with the substrate is relatively weak.

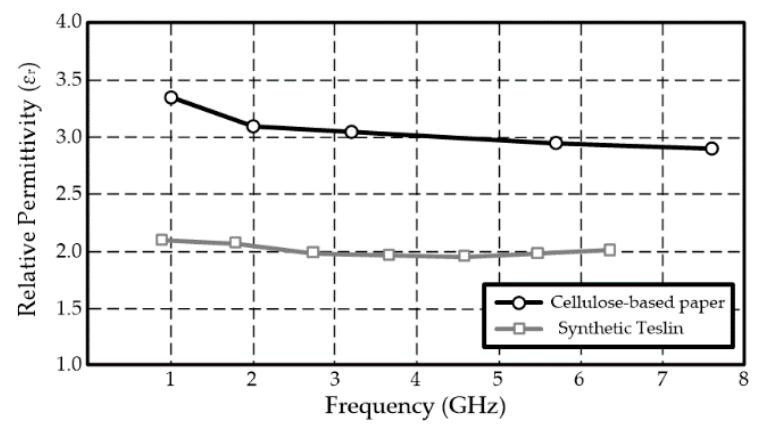

(a)

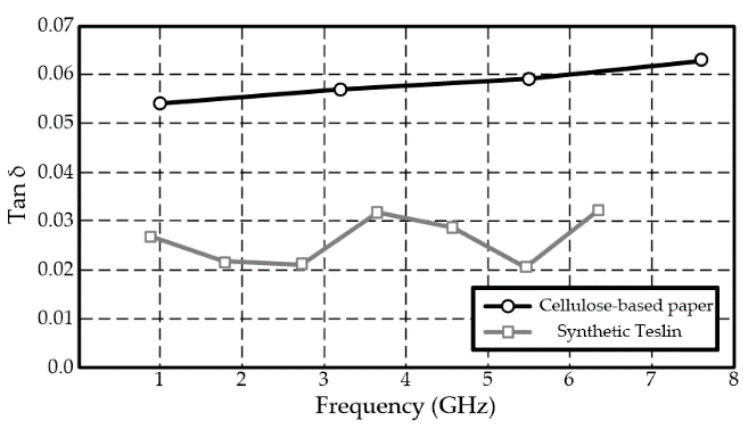

(b)

Figure 1. (a) Relative permittivity $\left(\varepsilon_{r}\right)$ of cellulose-based (black) and synthetic paper (gray) and (b) the loss tangent $(\tan \delta)$ of cellulose-based (black) and synthetic Teslin (gray). 


\subsubsection{Synthetic Teslin Paper}

Cellulose-based paper substrates suffer from durability issues when exposed to harsh environments or high temperatures for a long time. In this case, synthetic polymer-based papers, such as Teslin, are good alternatives. Teslin has the most advantages of cellulose-based polymer-coated papers. It is a flexible, environmentally friendly, and recyclable material. In addition, it is able to stand much higher thermal sintering temperatures (up to $220^{\circ} \mathrm{C}$ ) compared to cellulose-based polymer-coated paper. Teslin has been synthesized for printing applications and is a petroleum-free material, thus being non-toxic and recyclable. Teslin was characterized utilizing a printed ring resonator technique, and the $\varepsilon_{r}$ and $\tan \delta$ of a $0.25 \mathrm{~mm}$ thick Teslin are shown in Figure 1a,b (gray lines). The relative permittivity of Teslin is about 2.0 and the loss tangent is about $2.2 \times 10^{-2}$ at $1-8 \mathrm{GHz}$. Teslin has lower $\varepsilon_{r}$ and $\tan \delta$ values compared to cellulose-based paper.

\subsection{Metalization: Printed Thin Conductive Film}

In this section, two metallization methods using printing technology are presented: The direct printing of silver nano-particle ink and indirect printing of a copper $(\mathrm{Cu})$ thin film. The direct printing of silver nano-particle ink is simple and makes it easy to achieve a relatively high electrical conductivity and low surface roughness compared to indirectly printed $\mathrm{Cu}$ thin film. The indirect printing process of the $\mathrm{Cu}$ thin film involves the printing process of a $\mathrm{PdCl}_{2}$ seed layer and electroless plating. It requires more fabrication steps, but has a relatively thicker metal. It is also compatible with the soldering process.

\subsubsection{Inkjet-Printed Silver Nano-Particles}

Silver nano-particle inks are widely used for inkjet-printed electronics on various substrates, including paper substrates [6-12], because of their inherent capability to achieve a relatively low thermal sintering temperature and higher conductivity compared to other nano-particle-based inks, such as copper $(\mathrm{Cu})$ or gold $(\mathrm{Au})$ nano-particle inks [31,32]. The properties of a commonly used inkjet-printed silver nano-particle ink have been thoroughly studied in [33]. There are three main factors affecting the conductivity of the printed thin conductive films: The sintering process; the nano-particle concentration of the ink; and the number of printed layers [42-44]. The sintering process not only burns off the impurities and polymer coating around the nano-particles, but also increases the bonds of printed nano-particles. Although the thermal sintering process is widely used because of its simplicity, various other types of sintering processes, such as laser, UV flash lamp, and microwave sintering, have demonstrated uniform performance and high conductivity values. Typically, higher nano-particle concentrations and numbers of printed layers increase the conductive nano-particle density of the printed traces, resulting in higher conductivity values. Nevertheless, a dense nano-particle density can result in clogging of the printer nozzles. Therefore, careful experimentation is necessary before large-scale/large-area implementation.

An atomic force microscope (AFM) scanned image of an inkjet-printed silver nano-particle thin film is shown in Figure 2. The sample was printed using a $10 \mathrm{pL}$ ink cartridge with $20 \mu \mathrm{m}$ (1024 dpi) droplet spacing on a glass substrate and it was thermally sintered at $150{ }^{\circ} \mathrm{C}$ for $2 \mathrm{~h}$ at atmospheric pressure [45]. The measured arithmetic average $\left(R_{a}\right)$ and root mean squared $\left(R_{q}\right)$ and roughness values were 11.4 and $14.4 \mathrm{~nm}$, respectively. The cross-sections of the inkjet-printed thin films, depending on the volume of the ink droplet ( 1 and $10 \mathrm{pL}$ ), are shown in Figure 3, for the same printer setting and sintering process. The cross-section of the traces was measured using a Dekktak profilometer. Each printed layer adds about $200 \mathrm{~nm}$ of thickness for $1 \mathrm{pL}$ cartridges (Figure 3a) and $500 \mathrm{~nm}$ of thickness for $10 \mathrm{pL}$ cartridges (Figure $3 \mathrm{~b}$ ). The maximum thickness of the inkjet-printed silver nano-particle ink depends on the interactions of the surface energies: The surface energy of the ink and the substrate surface $[46,47]$. The ink flows out to the side when the thickness of the printed silver nano-particle ink reaches the critical thickness. The coffee-ring effect was observed when the volume of ink droplets was 
high. This is caused by different solvent evaporation rates in the middle and at the edge of the printed droplet. For example, there was no coffee-ring effect for the 1-pL ink droplet, as shown in Figure 3a. The thickness of the printed traces on the glass substrate ranges from 0.2 to $3.0 \mu \mathrm{m}$. The conductivity values $(\sigma)$ of the printed thin films can be extracted using an equation- $\sigma=1 /(A \cdot R)(\mathrm{S} / \mathrm{m})(A$ : the cross-section area, $R$ : the measured resistance between two points of the trace)-with respective values shown in Figure 4 . The measured DC conductivity values were about $4.96 \times 10^{6} \mathrm{~S} / \mathrm{m}$ for the $1 \mathrm{pL}$ cartridge and $5.70 \times 10^{6} \mathrm{~S} / \mathrm{m}$ for the $10 \mathrm{pL}$ cartridge when the thermal sintering temperature was $150^{\circ} \mathrm{C}$. The conductivity value of the inkjet-printed silver nano-particles can be improved to $1.2 \times 10^{7} \mathrm{~S} / \mathrm{m}$ when the sintering temperature is higher than $200{ }^{\circ} \mathrm{C}$. This corresponds to $19.05 \%$ of a bulk silver's conductivity value $\left(\sigma_{\mathrm{Ag}}=6.3 \times 10^{7} \mathrm{~S} / \mathrm{m}\right)$. The conductivity value of the trace for $10 \mathrm{pL}$ cartridges is higher than that for a $1 \mathrm{pL}$ cartridge, since the $10 \mathrm{pL}$ cartridges can print more nano-particles per drop, which results in a higher nano-particle density per unit area than $1 \mathrm{pL}$ cartridges. The difference in the conductivity values becomes smaller as the number of printed layers is increased because the nanoparticle density is saturating as this occurs.

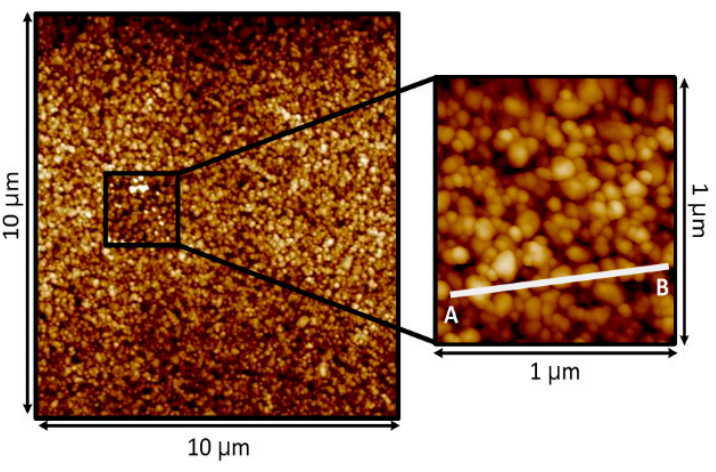

(a)

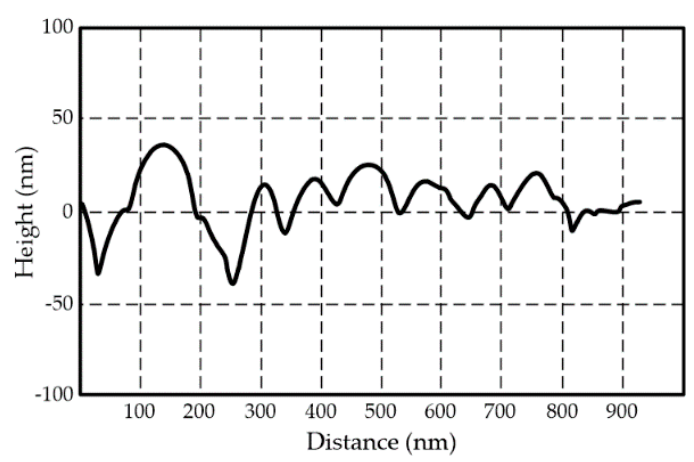

(b)

Figure 2. Surface of the inkjet-printed silver nano-particles: (a) Atomic force microscope (AFM) images of $10 \mu \mathrm{m} \times 10 \mu \mathrm{m}$ and $1 \mu \mathrm{m} \times 1 \mu \mathrm{m}$ areas, and (b) cross section of the line $\overline{\mathrm{AB}}$.

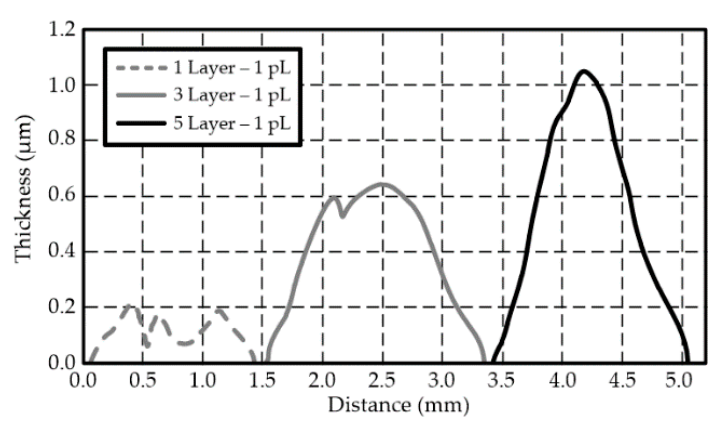

(a)

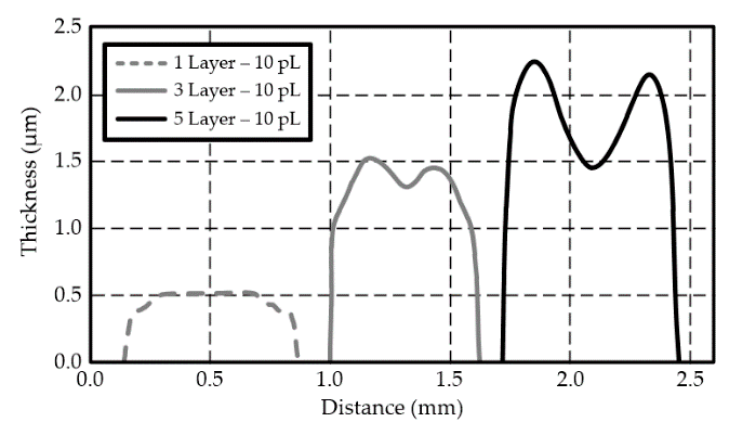

(b)

Figure 3. An inkjet-printed silver nano-particle-based metal trace as a function of the number of printed layers and the ink droplet volume: (a) $1 \mathrm{pL}$ (width: $1.0 \mathrm{~mm}$ ), and (b) $10 \mathrm{pL}$ (width: $0.5 \mathrm{~mm}$ ). 


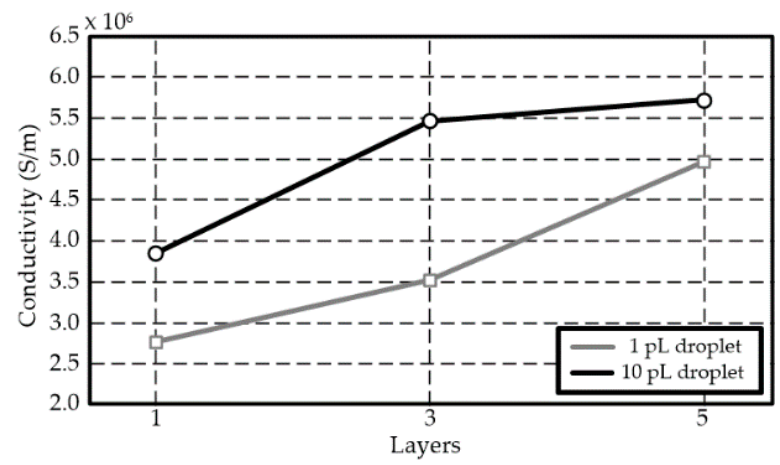

Figure 4. Conductivity values $\left(\sigma_{\mathrm{Ag}, 150{ }^{\circ} \mathrm{C}}\right)$ of an inkjet-printed silver nano-particle trace after thermal sintering at $150{ }^{\circ} \mathrm{C}$ with $20 \mu \mathrm{m}$ drop spacing (1024 dpi).

\subsubsection{Electroless Copper Deposition}

A catalyst-based inkjet printing process enables electroless conductor $(\mathrm{Cu}, \mathrm{Ag}$, etc.) deposition on virtually any substrate, while it eliminates numerous fabrication-related issues of the direct inkjet printing of metals, such as nozzle clogging, high-temperature sintering, and oxidation. As a proof of concept, the catalyst ink used for the on-paper copper deposition consists of palladium $(\mathrm{Pd})$, which is utilized to form a seed layer for copper growth [48]. The palladium catalyst ink is prepared by mixing palladium chloride $\left(\mathrm{PdCl}_{2}\right)$ and anhydrous ethanol at a ratio of 1:4. Glycerol is added to adjust the viscosity for inkjet printing. To demonstrate the process performance, the prepared palladium-based catalyst ink is loaded into the $10 \mathrm{pL}$ cartridge and printed on synthetic Teslin paper to form a seed layer for copper growth. Teslin with the inkjet-printed palladium seed layer is then immersed in the electroless copper solution at room temperature to grow the copper layer. The copper solution is comprised of a cupric sulfate $\left(\mathrm{CuSO}_{4}\right)$ and sodium potassium tartrate tetrahydrate $\left(\mathrm{C}_{4} \mathrm{H}_{4} \mathrm{KNaO}_{6} \cdot 4 \mathrm{H}_{2} \mathrm{O}\right)$, while an aqueous $\mathrm{NaOH}$ solution and formaldehyde are added to adjust the $\mathrm{pH}$ to 12.5. The copper-grown paper is washed in deionized (DI) water to clean up the leftover of the copper solution [48].

The overall reaction in this electroless deposition is shown in Figure 5. The complexant (potassium sodium tartrate) in the bath prevents copper precipitation in the copper solution bath and allows the copper solution bath to operate at a high $\mathrm{pH}$ value of 12.5 . Sodium hydroxide is added to the bath because the thermodynamic driving force for copper deposition becomes larger as the bath $\mathrm{pH}$ increases [49]. Metal $\mathrm{Pd}(0)$, instead of $\mathrm{Pd}(\mathrm{II})$ species, is utilized as the catalyst in the electroless copper deposition [50]. The printed $\operatorname{Pd}(0)$ particles on Teslin catalyze the oxidation of the formaldehyde in the bath to formic acid and the reduction of $\mathrm{Cu}^{2+}$ to $\mathrm{Cu}$. Copper deposition starts around $\mathrm{Pd}$ nuclei, and copper then grows laterally at the edge of the deposited copper. When the entire $\mathrm{PdCl}_{2}$ catalyst-seeded surface is covered with copper, the copper itself acts as a catalyst for the oxidation of the reductant so that the electroless copper deposition takes place continuously [51]. The density of the seed layer of $\mathrm{PdCl}_{2}$ on the substrate surface significantly affects the continuity of the copper coating, as well as the size of the copper particles [52]. Dense palladium-bearing catalytic sites enable the nucleation of a relatively high density of copper particles that can grow quickly during the electroless deposition to yield a conformal, continuous, and nano-crystalline copper coating. 


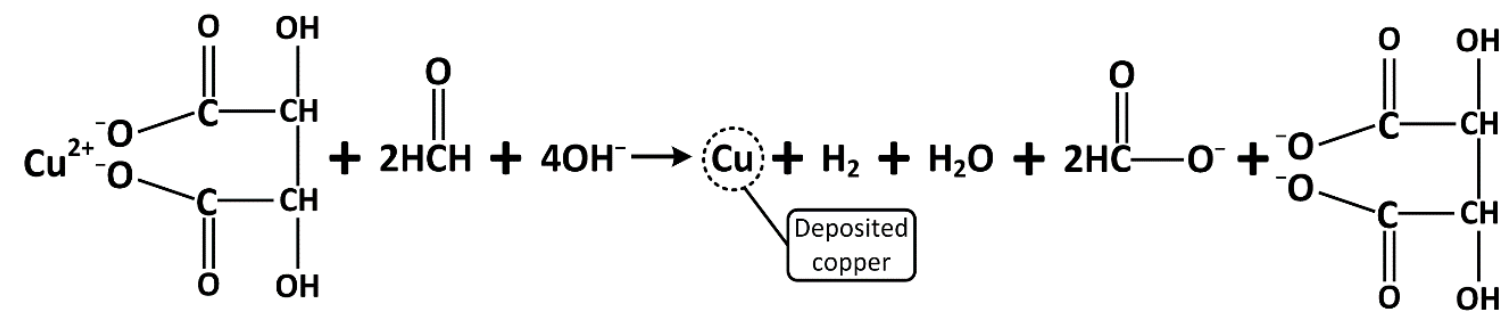

Figure 5. Chemical reaction of the inkjet-printed electroless copper deposition.

Figure 6a shows the copper deposited on paper utilizing the catalyst-based inkjet printing process in comparison with the inkjet-printed silver nanoparticle. The deposited copper thin film has a light brown color, and the printed silver nano-particles have a bright silver color (Figure 6a). The cross section (area (A) in Figure 6a) and the surface of the deposited copper on paper are shown in Figure $6 \mathrm{~b}, \mathrm{c}$, respectively. The thickness of the deposited copper thin film is thicker than the printed silver nano-particle when the electroless plating duration is longer than $50 \mathrm{~min}$. The paper with the inkjet-printed palladium seed layer is immersed in the copper bath for $50 \mathrm{~min}$ and the thickness of the grown copper layer is $3.87 \pm 0.9 \mu \mathrm{m}$ on average. The sheet resistance and the conductivity values of the deposited copper on paper for $50 \mathrm{~min}$ are $0.1 \Omega / \mathrm{sq}$. and $3.33 \times 10^{6} \mathrm{~S} / \mathrm{m}$, respectively (Figure 7). The conductivity value of the deposited copper on paper is about $5.6 \%$ of the bulk copper's conductivity $\left(\sigma_{\mathrm{Cu}}=5.96 \times 10^{7} \mathrm{~S} / \mathrm{m}\right)$ and it is similar to that of the inkjet-printed silver nanoparticle on paper sintered at $120^{\circ} \mathrm{C}$ for $2 \mathrm{~h}$ with five layers of printing $\left(\sigma_{\mathrm{Ag}, 120^{\circ} \mathrm{C}}=2.8 \times 10^{6} \mathrm{~S} / \mathrm{m}\right)$.

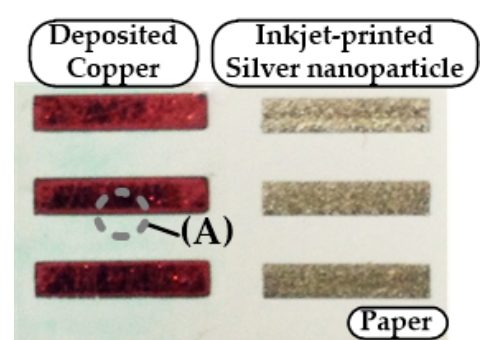

(a)

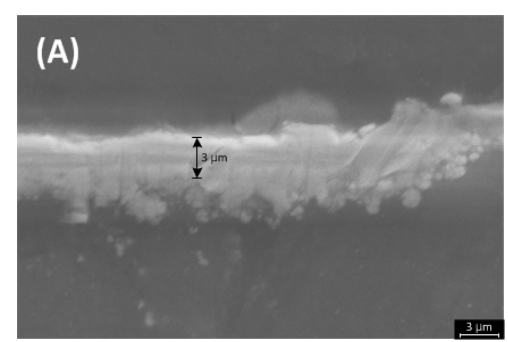

(b)

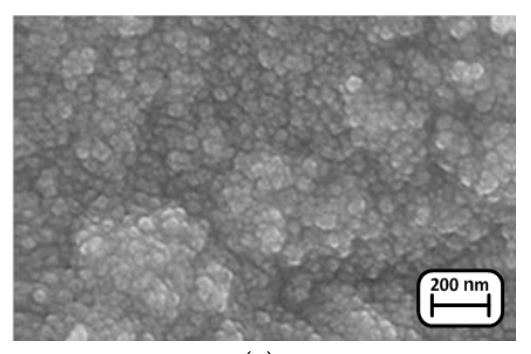

(c)

Figure 6. (a) The deposited copper traces (50 min) utilizing the palladium catalyst ink in comparison with the inkjet-printed silver nanoparticle traces. (b) Cross section and (c) surface of the copper grown on the cellulose-based paper.

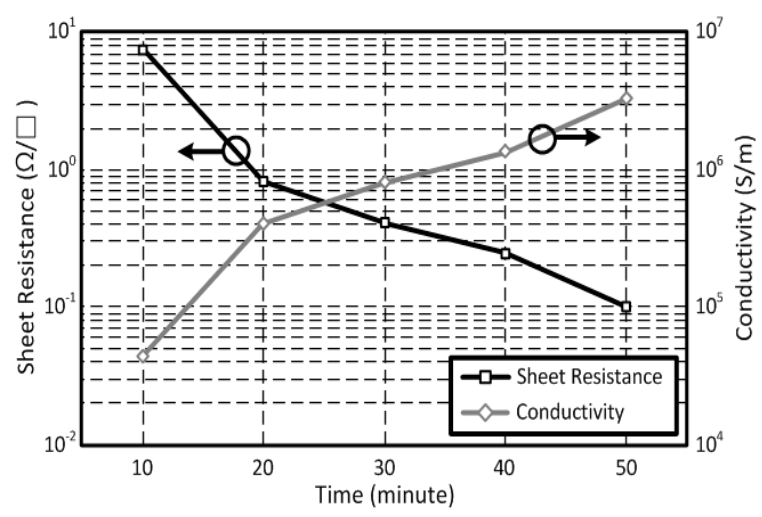

(a)

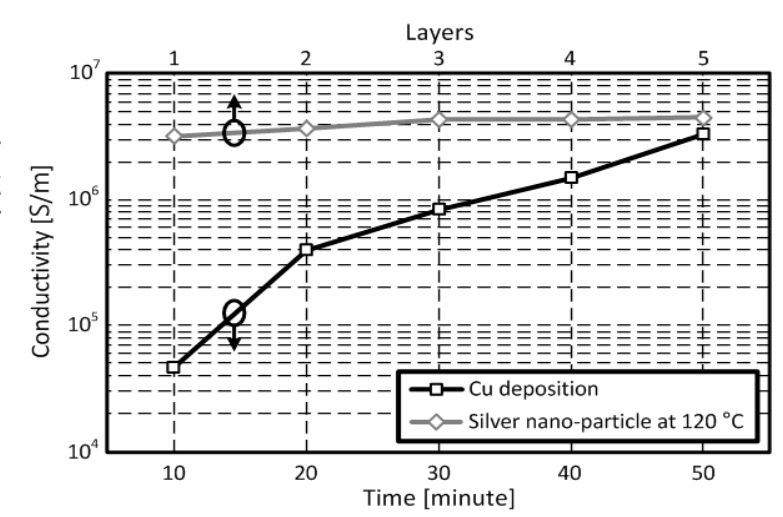

(b)

Figure 7. (a) Sheet resistance and conductivity values of the grown copper layer as a function of the immersion time in the copper bath and (b) conductivity values of the grown copper layer and the inkjet-printed silver nano-particle as a function of the development time in the copper bath and the printed layers. 


\subsection{Deielctric Ink: PVP and SU-8}

\subsubsection{Thick-Layer Dielectric Ink: SU-8}

To create multi-layer structures, dielectric inks are required. When designing RF structures such as planar antennas, thick dielectric layers are important for enabling a wider bandwidth and easier impedance matching. In this work, a thick-film dielectric ink, which can print dielectric layers with thicknesses in excess of $6 \mu \mathrm{m}$ per layer, is created. To produce thick layers, a polymer, which can be heavily loaded into a solvent while keeping the net viscosity low, is chosen. To formulate the ink, $35 \mathrm{w} \%$ SU-8 polymer with a UV-cross linker is dissolved in cyclopentanone. The solution is sonicated for $5 \mathrm{~min}$ to ensure complete dissolution of the polymer within the solvent. By increasing the weight concentration of the polymer in the ink, thicker layers can be obtained. To determine the maximum polymer loading within the solvent, which keeps the viscosity of the ink within a printable range, a parametric sweep of the polymer loading by weight is performed. Falling-ball measurements show the viscosity of the SU-8 ink to be $13 \mathrm{cP}$ at $25{ }^{\circ} \mathrm{C}$ when $35 \mathrm{w} \%$ of the polymer is loaded into cyclopentanone. The rheometric analysis is displayed in Figure 8a.

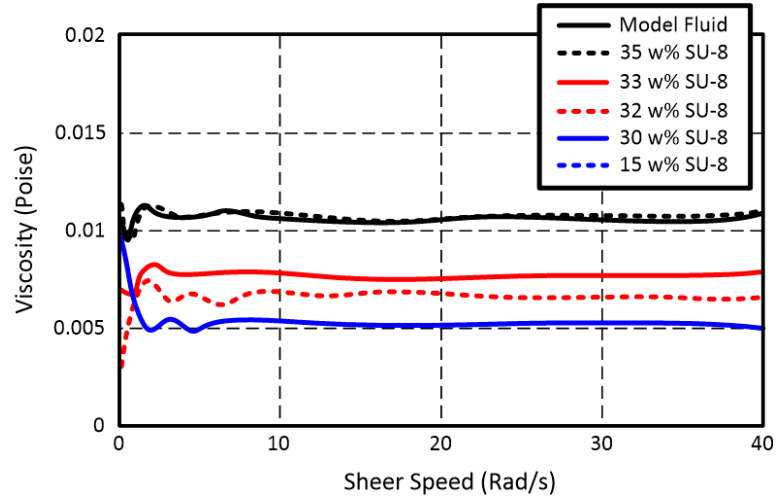

(a)

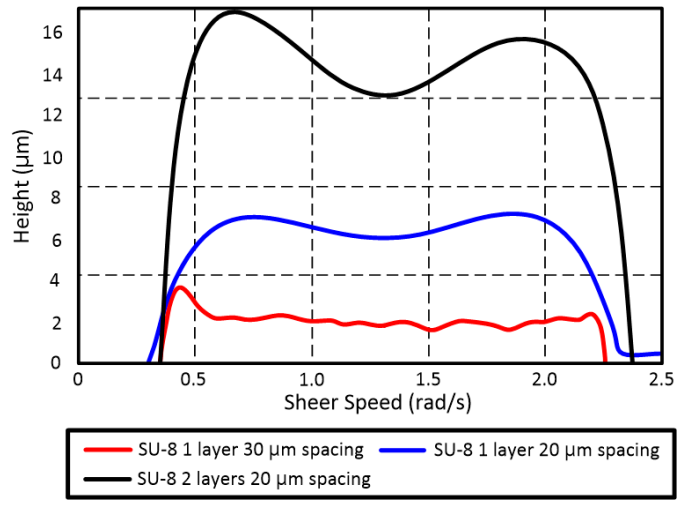

(b)

Figure 8. (a) Rheometric analysis and (b) thickness of inkjet-printed SU-8 ink.

To determine the thickness of the printed dielectric, square patterns are printed with 20 and $30 \mu \mathrm{m}$ drop spacing. The patterns are exposed to $365 \mathrm{~nm}$ UV light to initiate the photo-crosslinker, and then heated to $120^{\circ} \mathrm{C}$ for $5 \mathrm{~min}$ to complete polymerization of the film. The height of the film is measured using a stylus profilometer. It can be seen in Figure $8 \mathrm{~b}$ that with drop spacing of $20 \mu \mathrm{m}$, film thicknesses in excess of $7 \mu \mathrm{m}$ per layer can be patterned. Printing successive layers linearly increases the dielectric thickness. Performing a thermal reflow process after printing can decrease the surface roughness of the printed layers [53]. The SU-8 polymer is well-known in the Micro Electro Mechanical Systems (MEMS) field, and has been characterized up to a millimeter-wave frequency range. The material has a relative permittivity $\left(\varepsilon_{r}\right)$ of 3.5 with a loss tangent $(\tan \delta)$ of 0.03 at $1 \mathrm{GHz}$ [54].

\subsubsection{Thin-Layer Dielectric Ink: PVP}

While thick film dielectrics are essential for printed multi-layer RF components where large conductor spacing is required, thin-film dielectrics are also required for components such as metal-insulator-metal (MIM) capacitors featuring high capacitance values. To produce thin layers, the poly (4-vinylphenol) or PVP, which is a polymer commonly used in printed transistor gates, is adapted to the Dimatix printing platform. PVP is chosen as it can create high-viscosity solutions for low polymer contents within a solvent. To formulate the ink, 5\% by weight PVP is dissolved in 1-hexanol. A heat crosslinker-poly (melamine-co-formaldehyde)-is added at $0.5 \%$ by weight to enable polymerization of the PVP film above $80^{\circ} \mathrm{C}$. To determine the minimum polymer content by weight able to produce the thinnest films possible, a parametric sweep of the polymer loading by 
weight is performed. As shown in Figure 9a, for small concentrations of the polymer within the solvent, as low as $5 \%$ by weight, a viscosity within the printable range can be obtained. The very low polymer content can help produce much thinner layers, which could find applicability in various structures, such as printed thin-film capacitors.

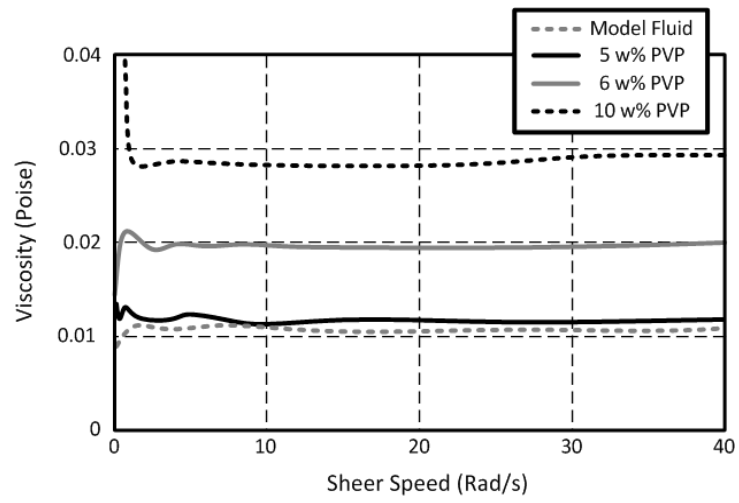

(a)

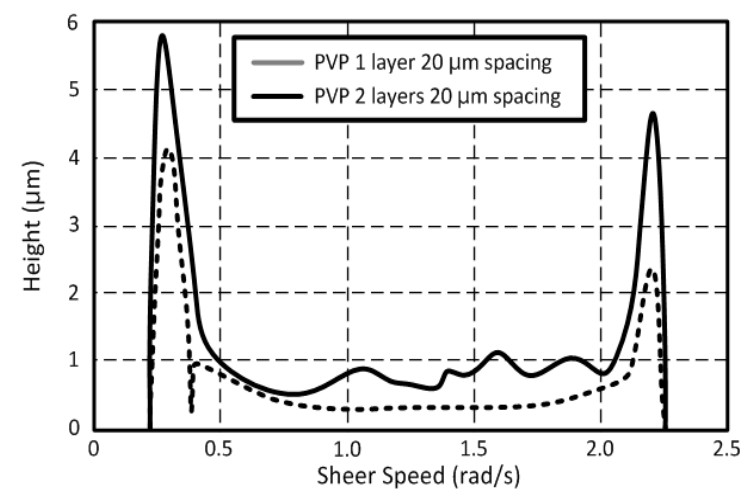

(b)

Figure 9. (a) Rheometric analysis and (b) thickness of the poly (4-vinylphenol) (PVP)-printed ink.

To determine the thickness of the printed PVP layers, square patterns are printed with $20 \mu \mathrm{m}$ drop spacing, and ramped up to $180{ }^{\circ} \mathrm{C}$ over the period of $30 \mathrm{~min}$ to polymerize and harden the films. The film profiles are then measured using a stylus profilometer. The results of one and two layers of printed PVP are shown in Figure 9b. The average thickness at the center of the films is approximately $300 \mathrm{~nm}$ per layer. It can be noticed that the side walls of the film are much higher than the center. This is a common issue with low-material content inks and is called the coffee-ring effect, which is caused by solvent evaporation. As inkjet-printing is a conformal deposition technique, successive printed layers require proper processes to alleviate the coffee-ring effect. This can be improved by a thermal reflow process or including lower vapor-pressure solvent modifiers to slow the drying time [53]. The PVP polymer is well-known as a spin-coated polymer, and has been characterized through low frequencies. The material has a relative permittivity $\left(\varepsilon_{r}\right)$ of 3.5 and an experimental loss tangent $(\tan \delta)$ of 0.015 at $1 \mathrm{GHz}[54]$.

\section{Inkjet-Printed Microwave Components and Devices}

\subsection{RFID Tag}

RFID tags are one of the most widely used printed electronics and have numerous applications. [55]. Figure 10 shows a designed and printed bowtie RFID tag for ultra-high frequency (UHF) band (915 MHz) application on synthetic Teslin paper. The width of the lines was $0.5 \mathrm{~mm}$ and the size of the tag was about $63.6 \times 26.7 \mathrm{~mm}^{2}$. The antenna is conjugate matched to $13-j 122 \Omega$, which is the impedance of the RFID chip (NXP's SL3ICS1002/1202) at $915 \mathrm{MHz}$. The minimum transmitted (Tx) power required to read the RFID tag is also shown in Figure 6. Voyantic Tagformance was utilized to measure the Tx power with a $1 \mathrm{MHz}$ step and $0.1 \mathrm{~dB}$ resolution of the Tx power. The interrogation distance was set to $60 \mathrm{~cm}$. The minimum Tx power required to read the inkjet-printed RFID tag on Teslin at $915 \mathrm{MHz}$ was $16 \mathrm{dBm}$ in the free space. The performance of the inkjet-printed far-field RFID tag was successfully demonstrated through this experiment. 


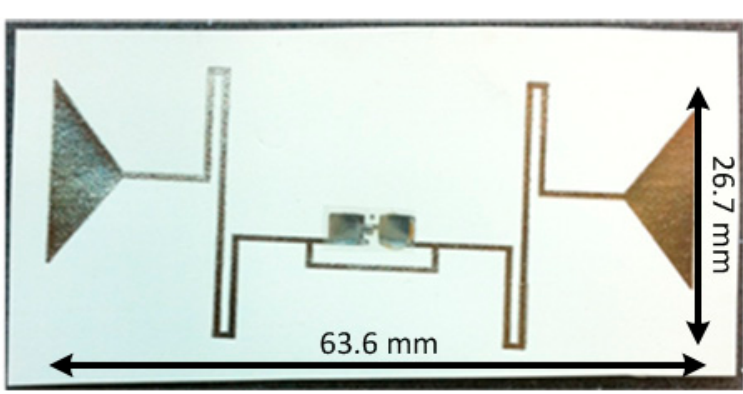

(a)

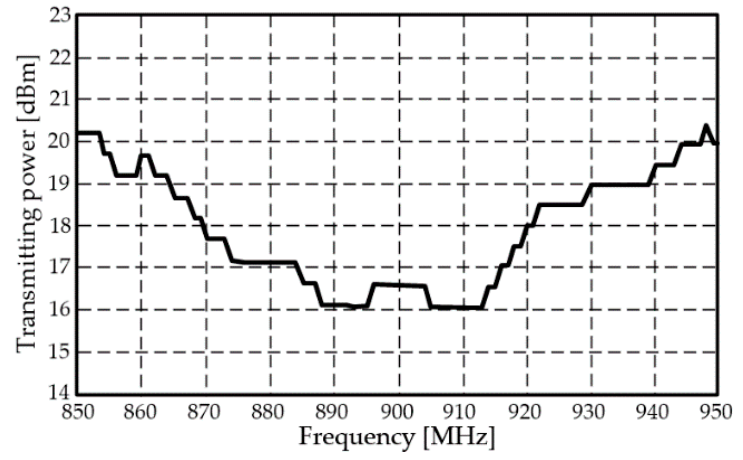

(b)

Figure 10. (a) Inkjet-printed radio frequency identification (RFID) tag on synthetic Teslin paper and (b) transmitted (Tx) power from the reader required to read the inkjet-printed RFID tag.

\subsection{Inkjet-Printed RFID-Enabled Sensor Utilizing Carbon Nanotubes (CNTs)}

RFID-enabled sensor systems have demonstrated a great potential as low-power, low-cost wireless sensor platforms [56-65] featuring a relatively simple architecture compared to conventional wireless sensor systems and good compatibility with conventional Wireless Sensor Networks (WSN) [66]. In this section, an inkjet-printed RFID-enabled CNT gas sensor is introduced, and Figure 11 shows its operation principle [67]. An RFID reader interrogates the sensor tag and its backscattered electromagnetic (EM) wave is monitored. The sensor tag has a sensor component that consists of an inkjet-printed single wall carbon nanotube (SWCNT) film acting like a tunable resistor. A resistance value is determined by the concentration of the sensing target gas, such as ammonia $\left(\mathrm{NH}_{3}\right)$ gas. The event decision (or gas detection) can be made by monitoring the backscattered wireless power levels because the electrical characteristics of the loaded SWCNT film vary due to different $\mathrm{NH}_{3}$ concentrations.

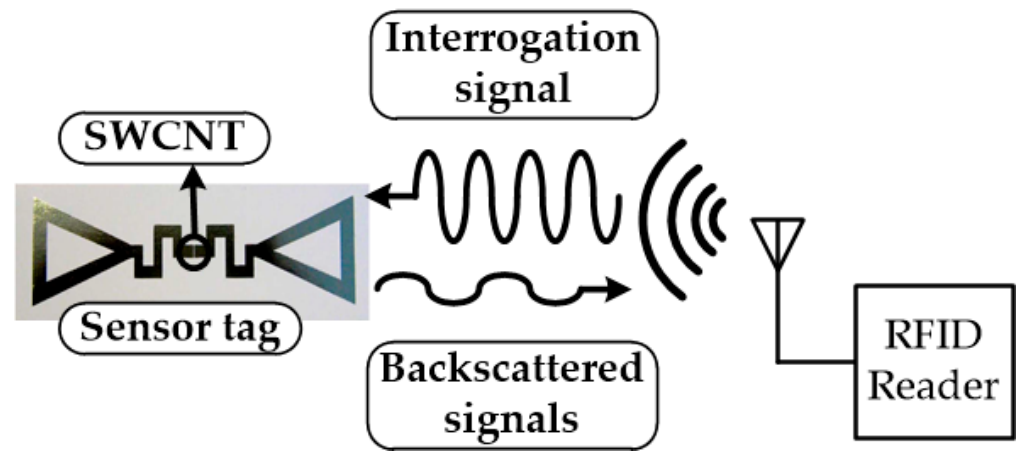

Figure 11. Operation principle of an RFID-enabled gas sensor utilizing single wall carbon nanotubes (SWCNTs).

The measured thickness of the 25-layer printed SWCNT film on cellulose paper was about $7 \mu \mathrm{m}$. At the European UHF RFID frequency band at $868 \mathrm{MHz}$, the impedance value of the inkjet-printed SWCNT film was $51.6-j 6.1 \Omega$ in air (no presence of $\mathrm{NH}_{3}$ gas), while the impedance value changed to $97.1-j 18.8 \Omega$ in $\mathrm{NH}_{3}$. The variation of the impedance and reflected power from the RFID-enabled SWCNT gas sensor are shown in Figure 12 to demonstrate the operation principle of the RFID-enabled sensor. The reflected power level of the sensor tag in air was $-18.4 \mathrm{~dB}$, while that of the sensor tag in $\mathrm{NH}_{3}$ was $-7.6 \mathrm{~dB}$. 


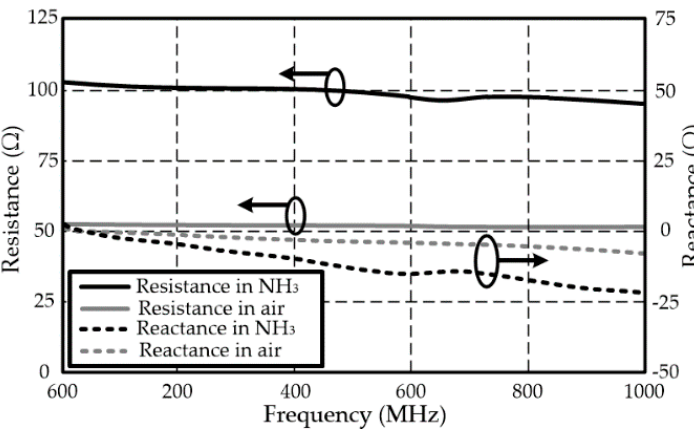

(a)

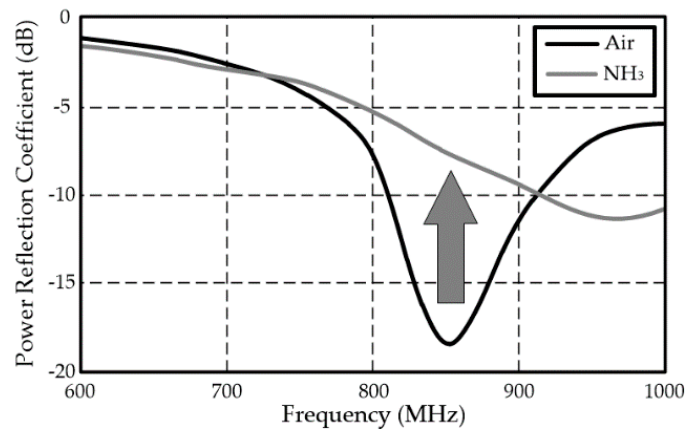

(b)

Figure 12. (a) Measured impedances of the SWCNT film which printed 25 layers in air/ $/ \mathrm{NH}_{3}$ and (b) the simulated power reflection coefficient of the RFID-enabled sensor with the SWCNT film before/after the gas exposure.

\subsection{Substrate-Integrated Waveguide (SIW) Structure and Via Fabrication}

Numerous RF applications require shielded/waveguide configurations due to requirements for reduced interference and/or a high power. Substrate-integrated waveguide (SIW) structures are similar to dielectric-filled waveguide structures, but feature more lightweight configurations due to the use of metalized via rows instead of solid metal walls. This topology is especially promising for microwave and millimeter-wave applications because it allows for whole-system integration on one substrate [68-70]. As a first step for realizing an inkjet-printed SIW structure on a paper substrate, via fabrication technology utilizing a copper rivet and conductive epoxy has been reported in [71] (Figure 13a). The via holes are drilled using a mechanical drill. This approach does not require any surface treatments and is a completely dry process. A laser drill is also a good candidate for the via hole drilling, but substrates, such as paper, can be damaged due to the heat generated by a laser drill. For the via hole metallization, copper rivets are inserted, and they are concealed using a conductive epoxy. The inset in Figure 13b shows a fabricated prototype of a microstrip-to-SIW transition. Its measured frequency responses $\left(\left|\mathrm{S}_{11}\right|\right.$ and $\left.\left|\mathrm{S}_{21}\right|\right)$ are also shown in Figure $13 \mathrm{~b}$. The dashed lines are reflection coefficients $\left(\left|\mathrm{S}_{11}\right|\right)$ and the solid lines are insertion loss $\left(\left|\mathrm{S}_{21}\right|\right)$ of the fabricated SIW structure. The transitions have been designed for an operation frequency above $5 \mathrm{GHz}$ with a cutoff frequency at $3.75 \mathrm{GHz}$. The pitch of the vias is $1.6 \mathrm{~mm}$ and the diameter of the via is $0.8 \mathrm{~mm}$. The substrate consists of three-layer stacked cellulose paper to achieve a thickness of $0.69 \mathrm{~mm}$. The insertion loss of the fabricated SIW component was $0.5 \mathrm{~dB} / \mathrm{cm}$ at the center of the pass band. The differences of the measurement and simulation were mainly due to the fabrication error and modeling issue of the conductive epoxy, which are not included in simulations because of the modeling simplicity.

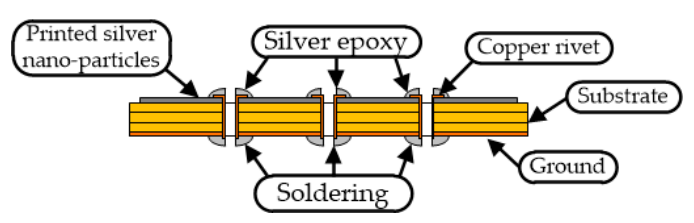

(a)

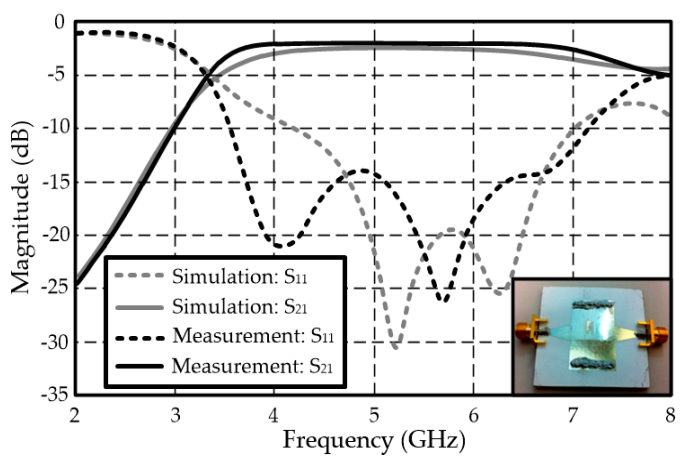

(b)

Figure 13. Inkjet-printed $\mu$ Strip-to-substrate-integrated waveguide (SIW) transition: (a) via fabrication on a paper substrate, and (b) the frequency response of the component. 
A fundamental step in producing fully-printed multi-layer via-enabled structures is the development of a stepped via profile on polymethyl methacrylate (PMMA) (Figure 14a). There have been several reported studies of fully printed vias [72-74]. However, these vias were implemented on thin polymer substrates with a thickness of less than $100 \mu \mathrm{m}$. Based on previous results, the stepped via profile was drilled to form a gradual transition from the top to bottom layer, as shown in Figure 14a [75].

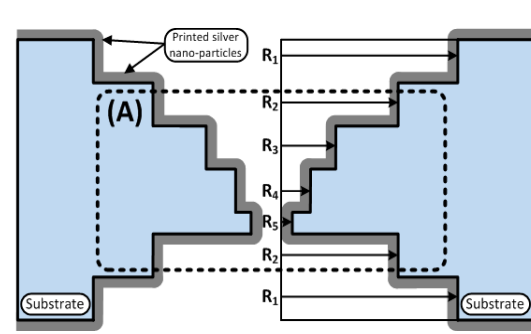

(a)

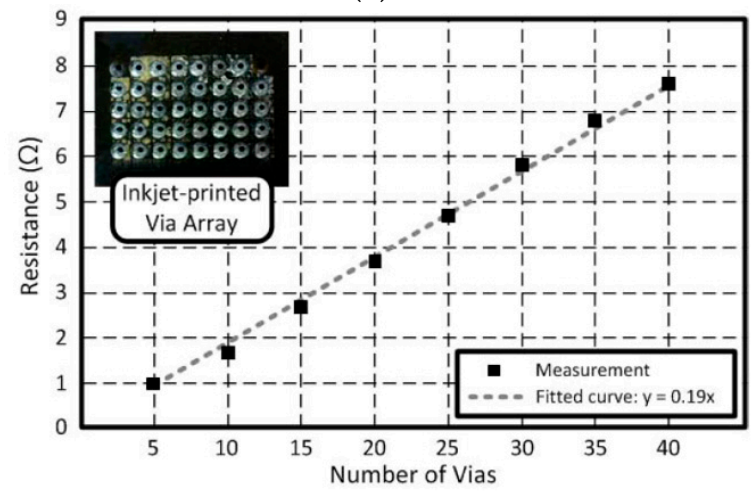

(c)
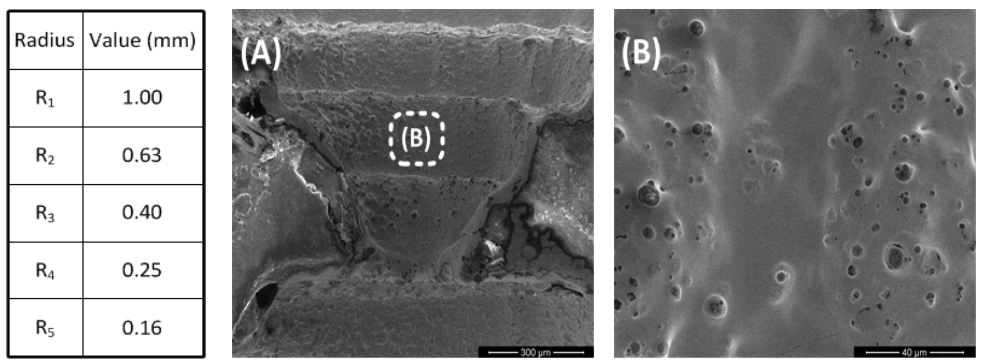

(b)

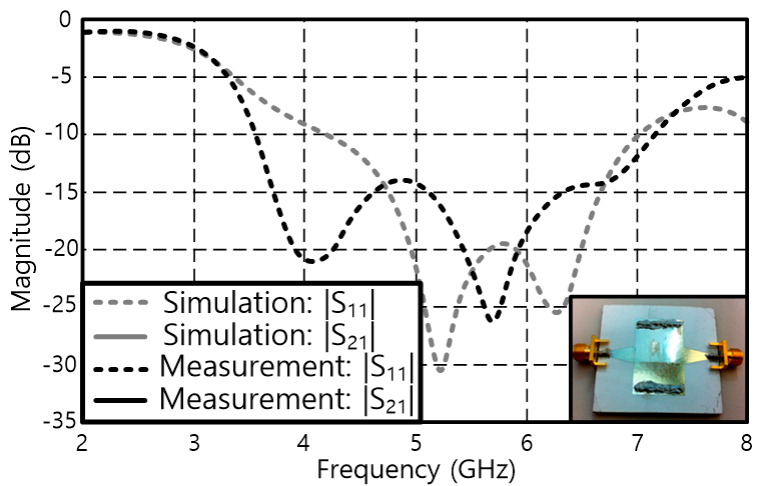

(d)

Figure 14. Geometry of a stepped via hole on a polymer substrate (PMMA): (a) Cross-section of the stepped via hole; (b) SEM images of the fully inkjet-printed stepped via hole; (c) series of 40 connected printed stepped vias; and (d) microstrip-to-SIW transition with printed stepped via walls.

The stepped via hole was drilled using a $\mathrm{CO}_{2}$ laser, and five layers of silver nanoparticles were printed on both the top and bottom sides of each substrate. The SEM images of the inkjet-printed stepped via hole showed a continuous inkjet-printed silver nano-particle layer (Figure 14b). Figure 14b-(A) corresponds to the dashed box in Figure 14a, and Figure 14b-(B) corresponds to the dashed box in Figure 14b-(A). A single inkjet-printed stepped via hole on a $1 \mathrm{~mm}$ thick PMMA substrate had a resistance of $7.4 \Omega$. This result verified the feasibility of the implementation of inkjet-printed via-enabled multi-layer structures on various substrates. Figure $14 \mathrm{c}$,d presents design examples using the proposed inkjet-printed stepped via structure. A series of 40 connected printed stepped vias on $0.8 \mathrm{~mm}$ thick RT/Duroid 5880 [76] only has a resistance value of $7.8 \Omega$. The measured S-parameters of a microstrip-to-SIW transition with $1 \mathrm{~mm}$ thick stepped via walls show good agreement with the simulation.

\subsection{Hybrid Printed Electronics}

Hybrid printed electronics usually consist of printed passive components, a circuit layout, and soldered/bonded surface mount devices (SMDs). High-Q inductors, capacitors, and integrated circuits (ICs), in various package types and sizes, can be integrated on a flexible printed circuit board. This results in a good flexibility and high performance because the advantages of printing technology and surface mounting technology are converged. Many reported hybrid printed electronics have soldered or bonded circuit components on printed flexible polymer or paper substrates [77-84]. In this paper, two design examples of hybrid printed electronics are introduced. A solar-powered 
active antenna reported in [51] designed and implemented an oscillator on an inkjet-printed antenna. It demonstrated the possibility of hybrid printed electronics, but a limitation was clear-the soldering process was not compatible with the inkjet-printed silver nano-particle layout. An indirect copper printing technology was developed in order to enable the soldering process [48].

\subsubsection{Solar Powered Active Antenna on Paper}

Besides the passive components on paper substrates, inkjet printing technology has successfully implemented more complicated systems including active components. An inkjet-printed active antenna on paper for wireless power transfer and identification has been reported in [85]. The fabricated solar-powered beacon oscillator (active antenna) operates at around $800 \mathrm{MHz}$ and consists of a slot antenna, voltage-controlled oscillator, voltage regulator, and solar cells (Figure 15a). It is hybrid printed electronics technology that takes advantage of nano-particle printing and cutting-edge discrete silicon devices. The oscillation frequency can be scaled up to any desired operation frequency. For stable oscillation of the oscillator, a $1.8 \mathrm{~V}$ voltage regulator was integrated with solar cells to supply self-sustainable power to the active antenna system. The performance of the inkjet-printed beacon oscillator on paper was measured by using a spectrum analyzer (Figure 15a). The oscillation frequency was observed at $783.2 \mathrm{MHz}$ (Figure 15a) and the measured phase noise was about $-118 \mathrm{dBc} / \mathrm{Hz}$ at $1 \mathrm{MHz}$ away from the carrier frequency (Figure 15b). Its circuit schematic and fabricated oscillator on the inkjet printed circuit layout are shown in Figure 15c,d. Conductive silver epoxy was applied to connect circuit components.

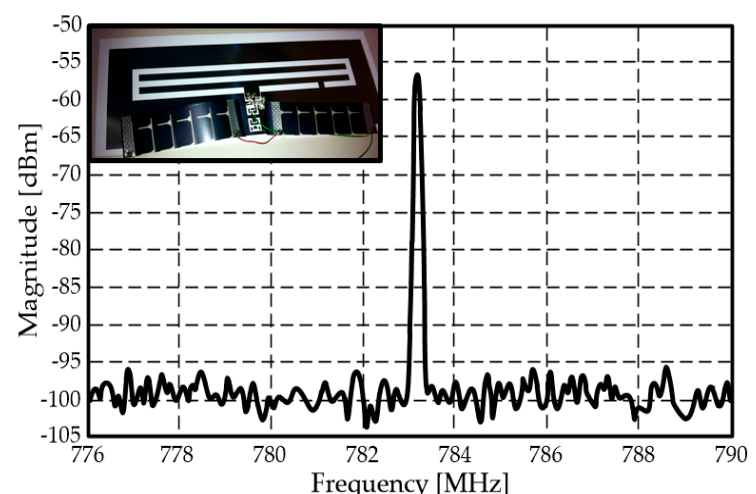

(a)

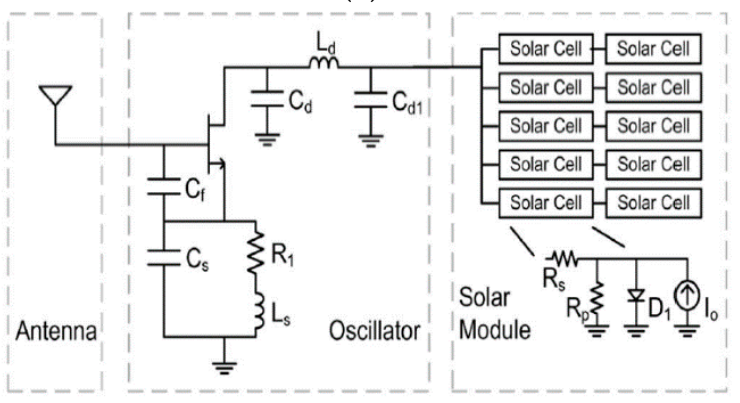

(c)

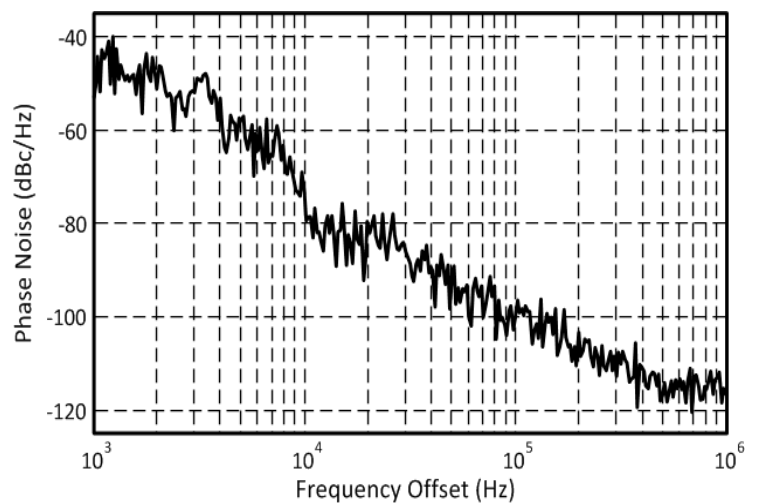

(b)

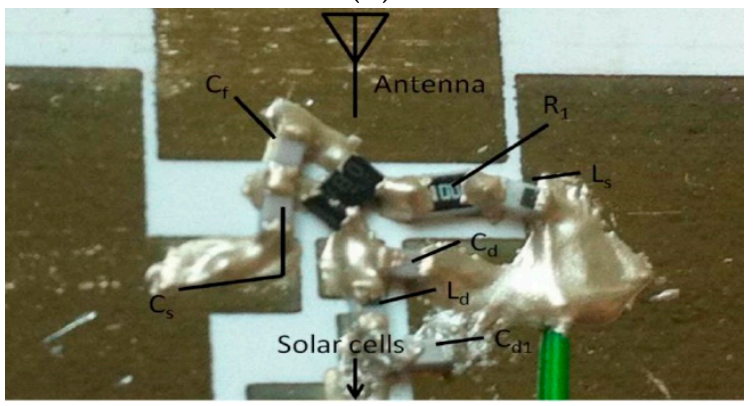

(d)

Figure 15. Active antenna on paper: Measured (a) spectrum; (b) phase noise; (c) system schematics; and (c) fabricated oscillator. 
The proposed active antenna can work as an RF source for energy harvesting-enabled self-sustainable or ultra-low power backscattering sensor systems [86]. For instance, it increases the ambient EM power density $\left(\mathrm{W} / \mathrm{m}^{2}\right)$ to wake up the RF energy harvester-enabled sensors. The sensor node rectifies ambient RF power to DC to operate analog/digital sensing circuits. For the backscattering system, each backscatterer reflects a single tone signal from the active antenna or a source. The backscatters modulate the incident wave by changing its load, enabling ultra-low power communication. This concept has been widely studied by many researchers, and there are many reported research efforts [87-90].

\subsubsection{Flexible RF Energy Harvester on Printed Copper}

Copper is compatible with the soldering process and low-cost material compared to silver. However, it is challenging to print copper directly due to its high sintering temperature [91,92]. Novel hybrid printed electronics using an indirect copper printing process were introduced in [93]. The circuit layout and antenna are printed and other circuit components, such as balun, diodes, and DC-DC converters, are soldered on the printed copper film, as shown in Figure 16. The proposed RF-DC converter consists of an antenna, charge pump for rectification, and DC-DC converter for voltage boosting, as shown in Figure 16a. The charge pump rectifies the RF signal and boosts the DC voltage to the threshold voltage of the DC-DC converter. The DC-DC converter steps up the input voltage and supplies power to a load. The fabricated system is shown in Figure 16b,c. Its performance is also shown in Figure 16c,d. The RF-DC rectifier fabricated on the indirectly printed copper showed good flexibility. It demonstrated a flexible RF energy harvester using a novel hybrid printed technology on low-cost polymer substrates such as Teslin [93]. The fabricated prototype generates an open circuit voltage of more than $2.9 \mathrm{~V}$ when it is exposed to a power density of around $1 \mu \mathrm{W} / \mathrm{cm}^{2}$ at a $900 \mathrm{MHz}$ UHF RFID frequency range. A low-power mode microcontroller is modeled as a $4.72 \mathrm{k} \Omega$ load since it drains about $200 \mathrm{nA}$ at $0.9 \mathrm{~V}$, as shown in Figure 16e. It shows that the designed RF energy harvester has successfully generated enough power to operate the low-power mode microcontroller continuously when it is able to harvest $0 \mathrm{dBm}$ RF power from the surrounding environment. 


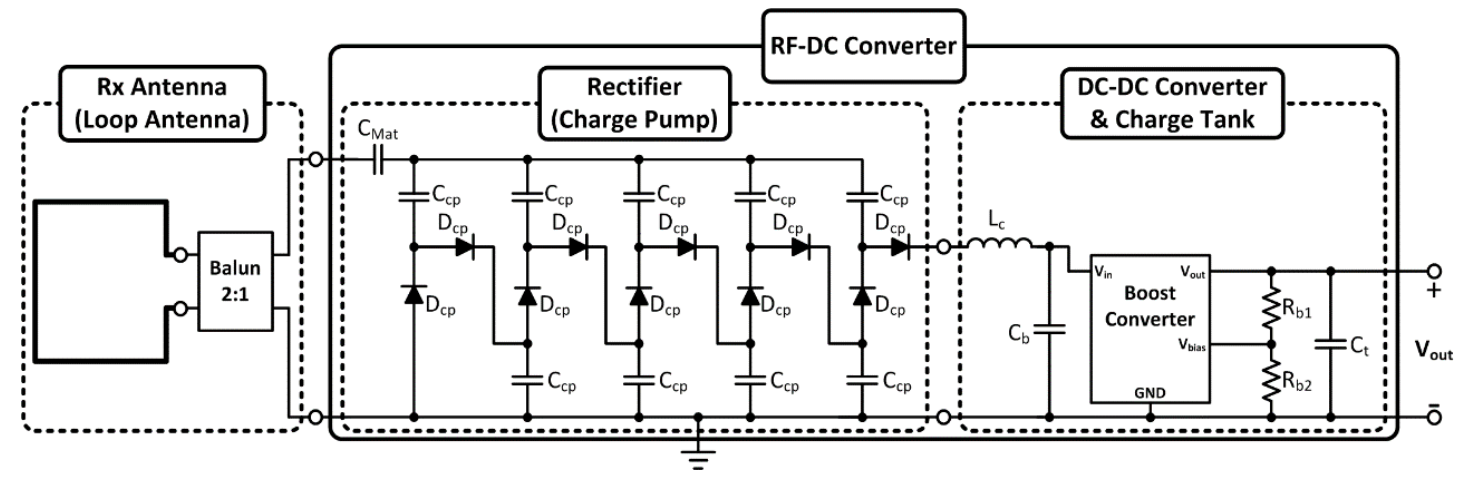

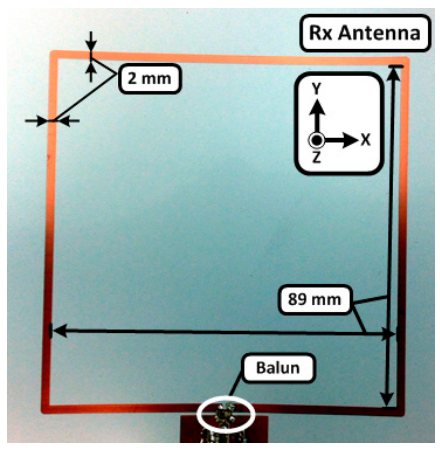

(b)

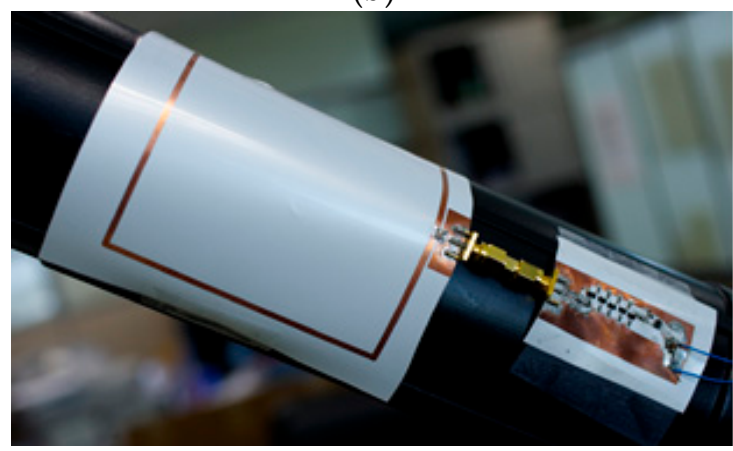

(d) (a)

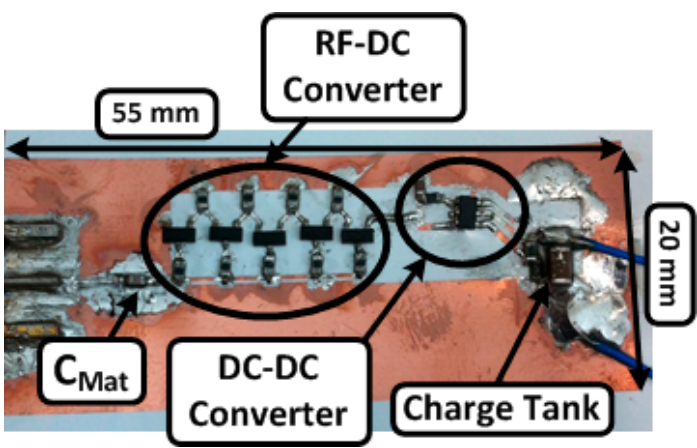

(c)

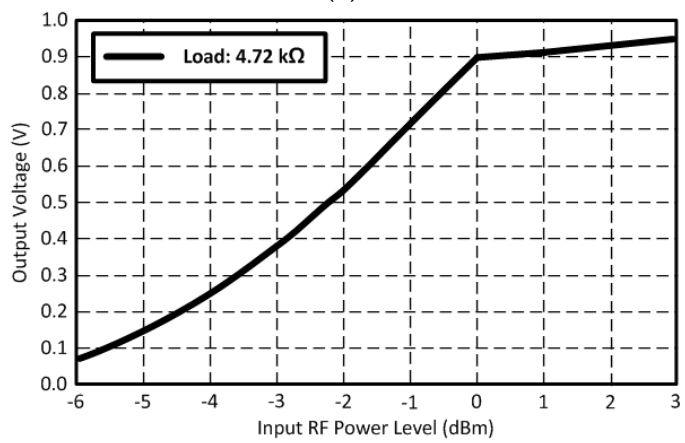

(e)

Figure 16. Far-field radio frequency (RF) energy harvesting system for a self-sustainable wireless sensor platform utilizing the hybrid printed electronic technology: (a) Circuit schematics; (b) square loop antenna; (c) RF-DC converter with a boost DC-DC converter, and the flexibility of the proposed hybrid printed RF energy harvester; (d) flexibility of the fabricated antenna and RF-DC converter; and (e) measured output voltage on a $4.72 \mathrm{k} \Omega$ load.

\subsection{Antennas on an Inkjet-Printed Artificial Magnetic Conductor (AMC) for Wearable Applications}

In this section, an inkjet-printed artificial magnetic conductor (AMC) surface is discussed. The general structure of the AMC surface consists of a frequency selective surface (FSS) and a ground plane, as shown in Figure 17a. It is a sort of electromagnetic bandgap (EBG) structure or high impedance surface (HIS) that prohibits wave propagation at a certain frequency band [94]. Numerous shapes have been reported for AMC surfaces for various applications [95-100]. The AMC surface suppresses back radiation of an antenna and significantly improves the antenna gain. The distance between AMC and the antenna is relatively short $(\lambda / 4)$ because the phase of a reflected wave from the AMC surface results in constructive interference with the waves radiated from the antenna. However, waves radiated from an antenna experience destructive interference when the waves are reflected by a PEC surface since the reflected wave is out-of-phase. Therefore, the induced current on the AMC surface is in-phase with the current flow of the antenna. Recently, a reconfigurable meta-surface structure, such as a reconfigurable 
intelligent surface (RIS) for $5 \mathrm{G} / 5 \mathrm{G}+$ or $6 \mathrm{G}$, is attracting great interest [101-104]. The RIS reflects the incident wave in the desired reflection angle by adjusting the reactance of a unit cell.

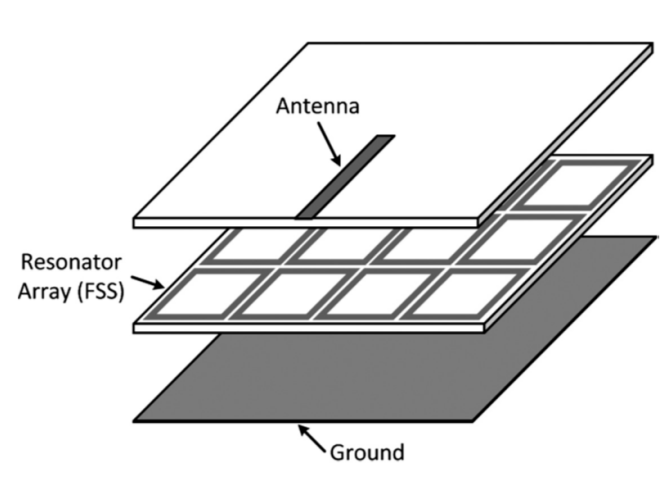

(a)

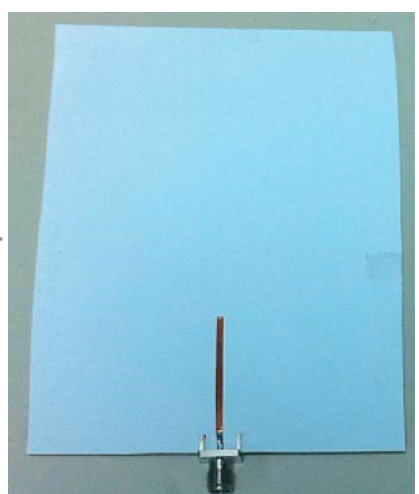

(b)

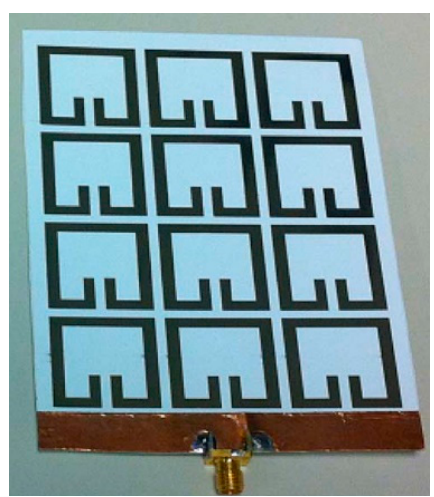

Figure 17. Inkjet-printed monopole antenna on the artificial magnetic conductor (AMC) plane: (a) Structure and (b) fabricated antenna.

There are unit cell shapes, and widely adopted unit cell shapes, split ring resonator (SRR) (Figure 18a) and single hair pin resonator types (Figure 18b), are shown as design examples. The phase response is a critical design parameter of the AMC surface because it indicates constructive or destructive interference. The reflected wave should have \pm 90 degrees to result in constructive interference with radiated waves from an antenna. As a design example, a monopole antenna was placed on a printed AMC reflector (Figure 17). Its AMC reflector consisted of a $3 \times 4$ hair pin type resonator array, as shown in Figure 18b. The designed antenna was mounted on a human body phantom to demonstrate the performance of the AMC reflector. The AMC reflector successfully suppressed the loading effect of the human phantom, as shown in Figure 19. The measured $\left|S_{11}\right|$ on the phantom was almost the same with the antenna in the free space (Figure 19a). There was a clear difference in gain values, as shown in Figure 19b. On the lossy human phantom, there was only about $0.2 \mathrm{~dB}$ gain drop at $2.45 \mathrm{GHz}$ with the $\mathrm{AMC}$ reflector, but about $4 \mathrm{~dB}$ gain drop was observed without the reflector. This clearly shows that the printed AMC reflector boosts antenna gain and isolates the antenna from the surrounding environment.

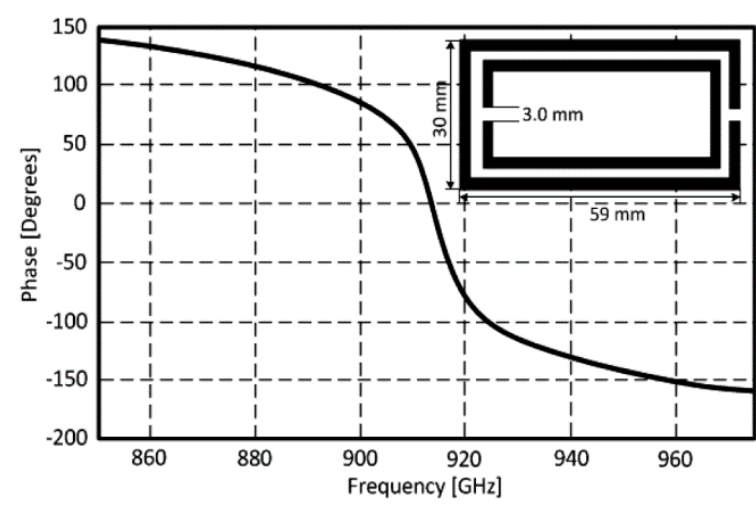

(a)

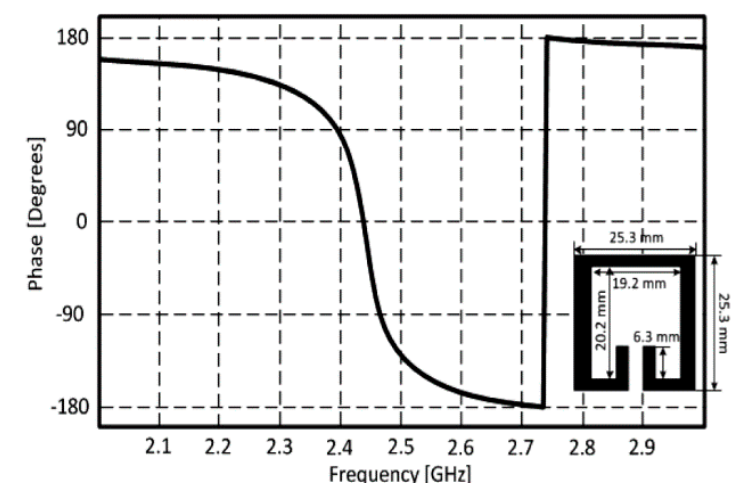

(b)

Figure 18. Resonator types for the AMC surface and their phase of the reflected wave: (a) Sprit-ring resonator (SRR) and (b) single hair pin resonator. 


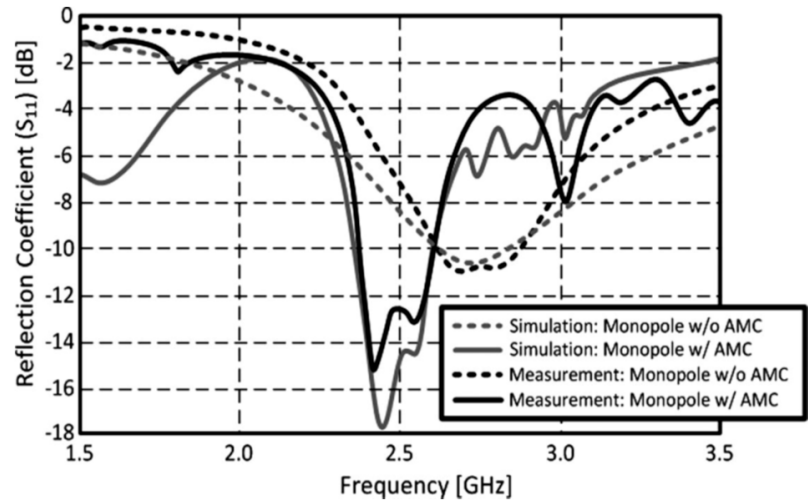

(a)

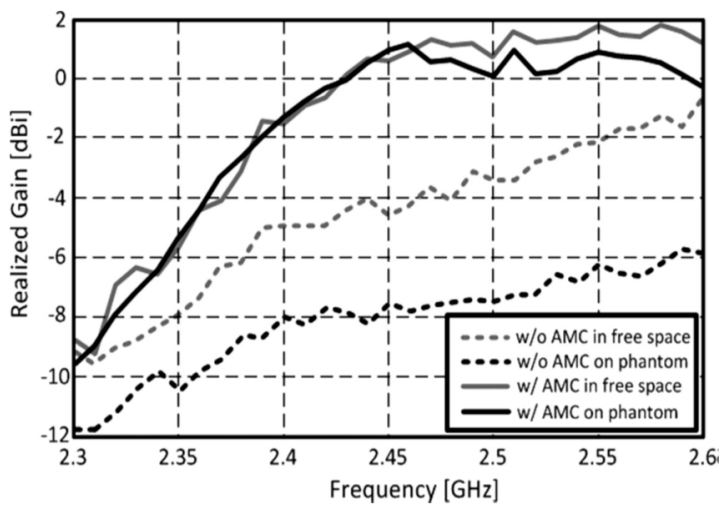

(b)

Figure 19. Measured antenna performance parameters: (a) Reflection coefficient $\left(\left|S_{11}\right|\right)$ and (b) gain.

The AMC reflector is also very useful for improving the communication range of the backscattering communication system, such as RFIDs, because it focuses electromagnetic energy in the desired direction. Figure 20a shows a structure of a dipole antenna on a $2 \times 3$ split ring resonator (SRR) array and inkjet-printed resonator array on cellulose paper (Figures 18a and 20b). It should be noted that the tag performance was significantly improved with the AMC reflector. The minimum required Tx power from a reader was reduced by about $6 \mathrm{~dB}$, as shown in Figure 20c. The packet loss ratio was measured using a software defined radio (SDR) USRP N200 [105] to control and record Rx/Tx signals, as shown in Figure 20. The communication range is almost doubled when an RFID tag is mounted on the proposed SRR resonator array [106].

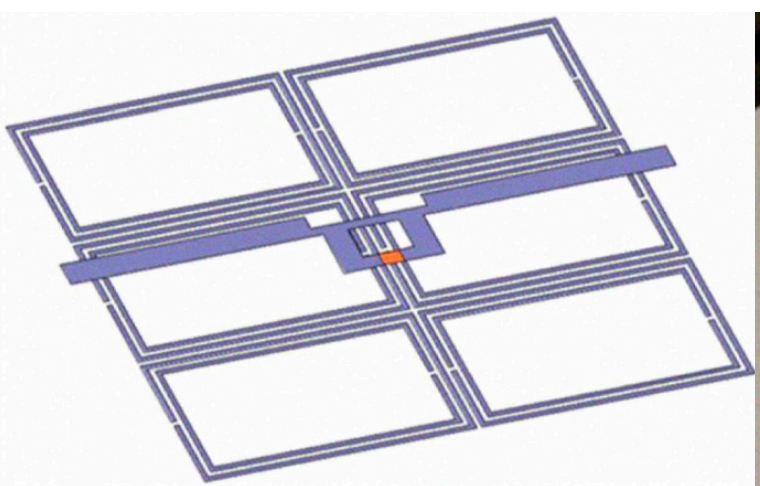

(a)

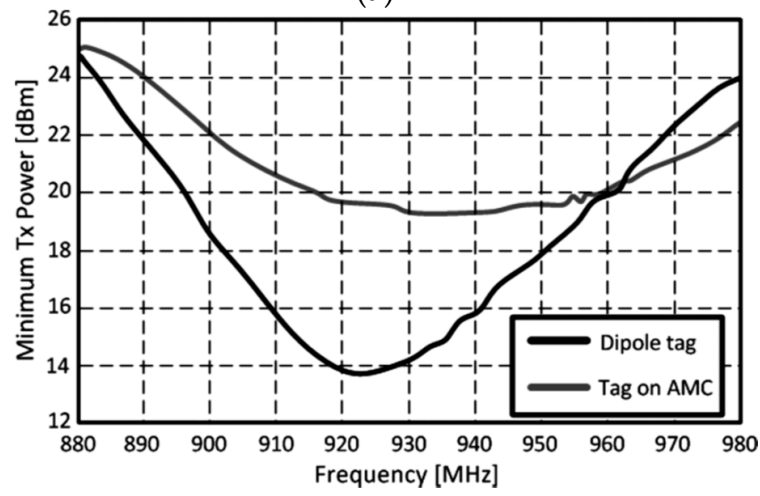

(c)

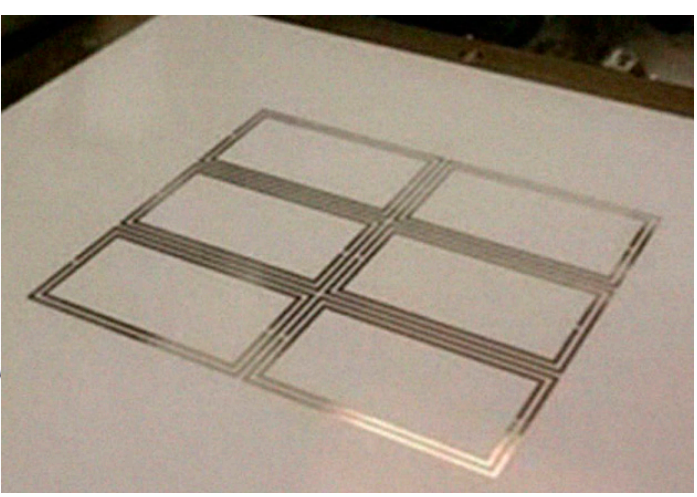

(b)

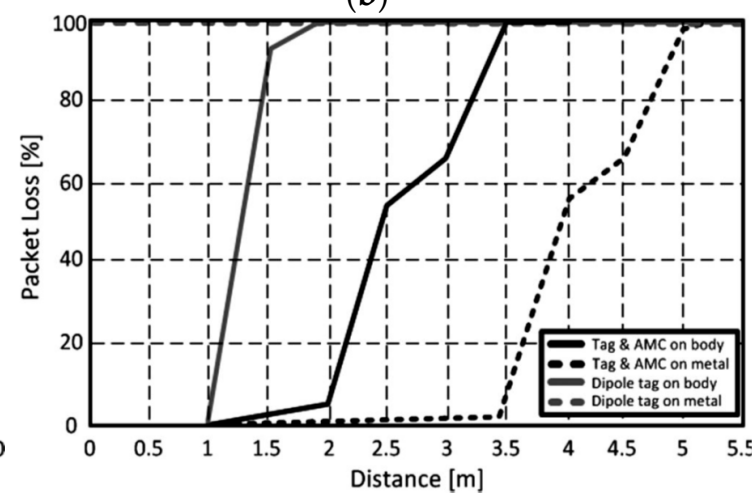

(d)

Figure 20. (a) Structure of the UHF dipole RFID antenna on an AMC reflector, and (b) the inkjet-printed split ring resonator (SRR) array. (c) Measured minimum Tx power required to read a tag and (d) tag read range. 


\section{Summary}

This paper has reviewed inkjet-printed paper electronics for microwave applications, including RFID, an RFID-enabled sensor, an SIW structure, via fabrication, an active antenna, RF energy harvesting, and an AMC surface. Important issues for printing thin conductive/dielectric films metalizing and designing the inkjet-printed RF electronics on paper have been discussed. This paper has also presented functional experimental prototypes as design examples. Inkjet-printed RF electronics on paper substrates represent a promising technology for practical ubiquitous "green" applications, such as Internet-of-Things (IoT), smart skins, and intelligent remote sensing configurations.

Funding: This work was supported by a National Research Foundation of Korea (NRF) grant funded by the Korean government (MSIT) (No. NRF-2020R1C1C1003362).

Conflicts of Interest: The author declares no conflict of interest.

\section{References}

1. Tobjörk, D.; Österbacka, R. Paper Electronics. Adv. Mater. 2011, 23, 1935-1961. [CrossRef] [PubMed]

2. Sun, Y.; Rogers, J.A. Inorganic Semiconductors for Flexible Electronics. Adv. Mater. 2007, 19, $1897-1916$. [CrossRef]

3. Siegel, A.C.; Phillips, S.T.; Dickey, M.D.; Lu, N.; Suo, Z.; Whitesides, G.M. Foldable Printed Circuit Boards on Paper Substrates. Adv. Funct. Mater. 2010, 20, 28-35. [CrossRef]

4. Kim, Y.H.; Moon, D.G.; Han, J.I. Organic TFT Array on a Paper Substrate. IEEE Electron Device Lett. 2004, 25, 702-704. [CrossRef]

5. Zschieschang, U.; Klauk, H. Organic Transistors on Paper: A Brief Review. J. Mater. Chem. C 2019, 7, 5522-5533. [CrossRef]

6. Lin, Y.; Gritsenko, D.; Liu, Q.; Lu, X.; Xu, J. Recent Advancements in Functionalized Paper-Based Electronics. ACS Appl. Mater. Interfaces 2016, 8, 20501-20515. [CrossRef]

7. Raut, N.C.; Al-Shamery, K. Inkjet Printing Metals on Flexible Materials for Plastic and Paper Electronics. J. Mater. Chem. C 2018, 6, 1618-1641. [CrossRef]

8. Agatea, S.; Joyce, M.; Lucia, L.; Pala, L. Cellulose and Nanocellulose-based Flexible-hybrid Printed Electronics and Conductive Composites-A Review. Carbohydr. Polym. 2018, 198, 249-260. [CrossRef]

9. Zhang, Y.; Zhang, L.; Cui, K.; Ge, S.; Cheng, X.; Yan, M.; Yu, J.; Liu, H. Paper-Based Electronics: Flexible Electronics Based on Micro/Nanostructured Paper. Adv. Mater. 2018, 30, 1870394. [CrossRef]

10. Barras, R.; Cunha, I.; Gaspar, D.; Fortunato, E.; Martins, R.; Pereira, L. Printable Cellulose-based Electroconductive Composites for Sensing Elements in Paper Electronics. Flex. Print. Electron. 2017, 2, 014006. [CrossRef]

11. Liu, H.; Qing, H.; Li, Z.; Han, Y.L.; Lin, M.; Yang, H.; Lie, L.; Lu, T.J.; Li, F.; Xu, F. Paper: A Promising Material for Human-friendly Functional Wearable Electronics. Mater. Sci. Eng. R: Rep. 2017, 112, 1-22. [CrossRef]

12. Nayak, L.; Mohanty, S.; Nayaka, S.K.; Ramadoss, A. A Review on Inkjet Printing of Nanoparticle Inks for Flexible Electronics. J. Mater. Chem. C 2019, 7, 8771-8795. [CrossRef]

13. Gu, Y.; Zhang, T.; Chen, H.; Wang, F.; Pu, Y.; Gao, C.; Li, S. Mini Review on Flexible and Wearable Electronics for Monitoring Human Health Information. Nanoscale Res. Lett. 2019, 14, 1-15. [CrossRef] [PubMed]

14. Gao, L.; Zhu, C.; Li, L.; Zhang, C.; Liu, J.; Yu, H.-D.; Huang, W. All Paper-Based Flexible and Wearable Piezoresistive Pressure Sensor. ACS Appl. Mater. Interfaces 2019, 11, 25034-25042. [CrossRef]

15. Kim, J.Y.; Park, S.H.; Jeong, T.; Bae, M.J.; Song, S.; Lee, J.; In, T.H.; Jung, D.; Yu, S. Paper as a substrate for inorganic powder electroluminescence device. IEEE Trans. Electron Devices 2010, 57, 1470-1474. [CrossRef]

16. Ding, M.; Liu, Y.; Wang, Y.; Jia, C.; Chen, P.; Duan, X.; Wang, C.; Song, F.; Li, M.; Wan, C.; et al. Solution-processable 2D semiconductors for high-performance large-area electronics. Nature 2018, 562, 254-258.

17. Ojo, A.A.; Mudiy, I.M. Electroplating of Semiconductor Materials for Applications in Large Area Electronics: A Review. Electronics 2018, 8, 262. [CrossRef] 
18. Sanz-Robinson, J.; Moy, T.; Huang, L.; Rieutort-Louis, W.; Hu, Y.; Wagner, S.; Sturm, J.C.; Verma, N. Large-Area Electronics: A Platform for Next-Generation Human-Computer Interfaces. IEEE Trans. Emerg. Sel. Top. Circuits Syst. 2017, 7, 38-49. [CrossRef]

19. Burghartz, J.N.; Alavi, G.; Albrecht, B.; Deuble, T.; Elsobky, M.; Ferwana, S.; Harendt, C.; Mahsereci, Y.; Richter, H.; Yu, Z. Hybrid Systems-in-Foil-Combining the Merits of Thin Chips and of Large-Area Electronics. IEEE J. Electron Devices Soc. 2019, 7, 776-783. [CrossRef]

20. Vilan, A.; Aswal, D.; Cahen, D. Large-Area Ensemble Molecular Electronics: Motivation and Challenges. Chem. Rev. 2017, 117, 4248-4286. [CrossRef]

21. Gluhak, A.; Krco, S.; Nati, M.; Pfisterer, D.; Mitton, N.; Razafindralambo, T. A Survey on Facilities for Experimental Internet of Things Research. IEEE Commun. Mag. 2011, 49, 58-67. [CrossRef]

22. Sirringhaus, H.; Kawase, T.; Friend, R.H.; Shimoda, T.; Inbasekaran, M.; Wu, W.; Woo, E.P. High-Resolution Inkjet Printing of All-polymer Transistor Circuits. Science 2000, 290, 2123-2126. [CrossRef] [PubMed]

23. Calvert, P. Inkjet Printing for Materials and Devices. Chem. Mater. 2001, 13, 3299-3305. [CrossRef]

24. Perelaer, J.; Gans, B.J.; Schubert, U.S. Ink-jet Printing and Microwave Sintering of Conductive Silver Tracks. Adv. Mater. 2006, 18, 2101-2104. [CrossRef]

25. Wijshoff, H. Drop Dynamics in the Inkjet Printing Process. Curr. Opin. Colloid Interface Sci. 2018, 36, $20-27$. [CrossRef]

26. Gans, B.J.; Duineveld, P.C.; Schubert, U.S. Inkjet printing of polymers: State of the art and future developments. Adv. Mater. 2004, 16, 203-213. [CrossRef]

27. Fuller, S.B.; Wilhelm, E.J.; Jacobson, J.M. Ink-jet Printed Nanoparticle Microelectromechanical Systems. J. Microelectromech. Syst. 2002, 11, 54-60. [CrossRef]

28. Kim, D.; Moon, J. Highly Conductive Ink Jet Printed Films of Nanosilver Particles for Printable Electronics. Electrochem. Solid-State Lett. 2005, 8, 30-33. [CrossRef]

29. Vyas, R.; Lakafosis, V.; Lee, H.; Shaker, G.; Yang, L.; Orecchini, G.; Traille, A.; Tentzeris, M.M.; Roselli, L. Inkjet Printed, Self Powered, Wireless Sensors for Environmental, Gas and Authentication-based Sensing. IEEE Sens. J. 2011, 11, 3139-3152. [CrossRef]

30. Park, J.U.; Hardy, M.; Kang, S.J.; Barton, K.; Adair, K.; Mukhopadhyay, D.K.; Lee, C.Y.; Strano, M.S.; Alleyne, A.G.; Georgiadis, A.G.; et al. High-resolution Electrohydrodynamic Jet Printing. Nat. Mater. 2007, 6, 782-789. [CrossRef]

31. Lee, Y.; Choi, J.R.; Lee, K.J.; Stott, N.E.; Kim, D. Large-scale Synthesis of Copper Nanoparticles by Chemically Controlled Reduction for Applications of Inkjet-printed Electronics. Nanotechnology 2008, 19, 415604. [CrossRef] [PubMed]

32. Chow, E.; Herrmann, J.; Barton, C.S.; Raguse, B.; Wieczorek, L. Inkjet-printed Gold Nanoparticle Chemiresistors: Influence of Film Morphology and Ionic Strength on the Detection of Organics Dissolved in Aqueous Solution. Anal. Chim. Acta 2009, 632, 135-142. [CrossRef] [PubMed]

33. Yang, L.; Rida, A.; Vyas, R.; Tentzeris, M.M. RFID Tag and RF Structures on a Paper Substrate using Inkjet-printing Technology. IEEE Trans. Microw. Theory Tech. 2007, 55, 2894-2901. [CrossRef]

34. Available online: https://www.teslin.com/en-US/Home.aspx/ (accessed on 2 October 2020).

35. Available online: http://www.kodak.com/ (accessed on 2 October 2020).

36. Latti, K.P.; Kettunen, M.; Stoem, J.P.; Silventoinen, P. A Review of Microstrip T-Resonator Method in Determining the Dielectric Properties of Printed Circuit Board Materials. IEEE Trans. Instrum. Meas. 2007, 56, 1845-1850. [CrossRef]

37. Thompson, D.; Tantot, O.; Jallageas, H.; Phonchak, G.E.; Tentzeris, M.M.; Papapolymerou, J. Characterization of Liquid Crystal Polymer (LCP) Material and Transmission Lines on LCP Substrates from 30 to $110 \mathrm{GHz}$. IEEE Trans. Microw. Theory Tech. 2004, 53, 1343-1352. [CrossRef]

38. Maza, A.R.; Cook, B.; Jabbour, G.; Shamim, A. Paper-based Inkjet-printed Ultra-wideband Fractal Antennas. IET Microw. Antennas Propag. 2012, 6, 1366-1373. [CrossRef]

39. Manteghi, M.; Rahmat-Samii, Y. A Novel UWB Feeding Mechanism for the TEM Horn Antenna, Reflector IRA, and the Vivaldi Antenna. IEEE Antennas Propag. Mag. 2004, 46, 81-87. [CrossRef]

40. Shaker, G.; Safavi-Naeini, S.; Sangary, N.; Tentzeris, M.M. Inkjet Printing of Ultrawideband (UWB) Antennas on Paper-based Substrates. IEEE Antennas Wireless Propag. Lett. 2011, 10, 111-114. [CrossRef] 
41. Saghlatoon, H.; Björninen, T.; Sydänheimo, L.; Tentzeris, M.M.; Ukkonen, L. Inkjet-Printed Wideband Planar Monopole Antenna on Cardboard for RF Energy-Harvesting Applications. IEEE Antennas Wirel. Propag. Lett. 2015, 14, 325-328. [CrossRef]

42. Maekawa, K.; Yamasaki, K.; Niizeki, T.; Mita, M.; Matsuba, Y.; Terada, N.; Saito, H. Drop-on-demand Laser Sintering with Silver Nanoparticles for Electronics Packaging. IEEE Trans. Compon. Pack. Manuf. Technol. 2012, 2, 868-877. [CrossRef]

43. Polzinger, B.; Schoen, F.; Matic, V.; Keck, J.; Willeckm, H.; Eberhardt, W.; Kueck, H. UV-sintering of Inkjet-Printed Conductive Silver Tracks. In Proceedings of the 11th IEEE International Conference on Nanotechnology, Portland, OR, USA, 15-18 August 2011.

44. Allen, M.; Alastalo, A.; Suhonen, M.; Mattila, T.; Leppäniemi, J.; Seppa, H. Contactless Electrical Sintering of Silver Nanoparticles on Flexible Substrates. IEEE Trans. Microw. Theory Tech. 2011, 59, 1419-1429. [CrossRef]

45. Kim, S.; Mariotti, C.; Alimenti, F.; Mezzanotte, P.; Georgiadis, A.; Collado, A.; Roselli, L.; Tentzeris, M.M. No Battery Required. IEEE Microw. Mag. 2013, 14, 66-77. [CrossRef]

46. Soltmanm, D.; Subramanian, V. Inkjet-printed Line Morphologies and Temperature Control of the Coffee Ring Effect. Langmuir 2008, 24, 2224-2231. [CrossRef] [PubMed]

47. Singh, M.; Haverinen, H.M.; Dhagat, P.; Jabbour, G.E. Inkjet Printing-process and its Applications. Adv. Mater. 2009, 22, 673-685. [CrossRef]

48. Cook, B.S.; Fang, Y.; Kim, S.; Le, T.; Goodwin, W.B.; Sandhage, K.H.; Tentzeris, M.M. Inkjet Catalyst Printing and Electroless Copper Deposition for Low-cost Patterned Microwave Passive Devices on paper. Electron. Mater. Lett. 2013, 9, 669-676. [CrossRef]

49. Mallory, G.O.; Hajdu, J.B. Electroless Plating-Fundamentals and Applications; William Andrew Publishing/Noyes: New York, NY, USA, 1990.

50. Xu, L.; Liao, J.; Huang, L.; Ou, D.; Guo, Z.; Zhang, H.; Ge, C.; Gu, N.; Liu, J. Surface-bound Nanoparticles for Initiating Metal Deposition. Thin Solid Films 2003, 434, 121-125. [CrossRef]

51. Ohno, I. Electrochemistry of Electroless Plating. Mater. Sci. Eng. A-Struct. 1991, 146, 33-49. [CrossRef]

52. Fang, Y.N.; Berrigan, J.D.; Cai, Y.; Marder, S.R.; Sandhage, K.H. Syntheses of Nanostructured Cu- and Ni-based Micro-assemblies with Selectable 3-D Hierarchical Biogenic Morphologies. J. Mater. Chem. 2012, 22, 1305-1312. [CrossRef]

53. Schift, H.; Spreu, C.; Schleunitz, A.; Lee, J. Shape Control of Polymer Reflow Structures Fabricated by Nanoimprint Lithography. Microelectron. Eng. 2011, 88, 87-92. [CrossRef]

54. Cook, B.S.; Cooper, J.R.; Tentzeris, M.M. Multi-layer RF Capacitors on Flexible Substrates Utilizing Inkjet Printed Dielectric Polymers. IEEE Microw. Wirel. Compon. Lett. 2013, 23, 353-355. [CrossRef]

55. Sharif, A.; Ouyang, J.; Yan, Y.; Raza, A.; Imran, M.A.; Abbasi, Q.H. Low-Cost Inkjet-Printed RFID Tag Antenna Design for Remote Healthcare Applications. IEEE J. Electromagn. RF Microw. Med. Biol. 2019, 3, 261-268. [CrossRef]

56. Kim, S.; Kawahara, Y.; Georgiadis, A.; Collado, A.; Tentzeris, M.M. Low-cost Inkjet-printed Fully Passive RFID Tags for calibration-free Capacitive/haptic sensor Applications. IEEE Sens. J. 2015, 15, 3135-3145. [CrossRef]

57. Yang, L.; Zhang, R.; Staiculescu, D.; Wong, C.P.; Tentzeris, M.M. A Novel Conformal RFID-enabled Module Utilizing Inkjet-printed Antennas and Carbon Nanotubes for Gas-detection Applications. IEEE Antennas Wirel. Propag. Lett. 2009, 8, 653-656. [CrossRef]

58. Girbau, D.; Ramos, A.; Lazaro, A.; Rima, S.; Villarino, R. Passive Wireless Temperature Sensor Based on Time-coded UWB Chipless RFID Tags. IEEE Trans. Microw. Theory Tech. 2012, 60, 3623-3632. [CrossRef]

59. Potyrailo, R.A.; Surman, C.; Go, S.; Lee, Y.; Sivavec, T.; Morris, W.G. Development of Radio-frequency Identification Sensors Based on Organic Electronic Sensing Materials for Selective Detection of Toxic Vapors. J. Appl. Phys. 2009, 106, 124092. [CrossRef]

60. Occhiuzzi, C.; Paggi, C.; Marrocco, G. Passive RFID Strain-sensor Based on Meander-line Antennas. IEEE Trans. Antennas Propag. 2011, 59, 4836-4840. [CrossRef]

61. Virtanen, J.; Ukkonen, L.; Bjorninen, T.; Elsherbeni, A.Z.; Sydänheimo, L. Inkjet-printed Humidity Sensor for Passive UHF RFID Systems. IEEE Trans. Instrum. Meas. 2011, 60, 2768-2777. [CrossRef] 
62. Gao, J.; Sidén, J.; Nilsson, H.E.; Gulliksson, M. Printed Humidity Sensor with Memory Functionality for Passive RFID tags. IEEE Sens. J. 2013, 13, 1824-1834. [CrossRef]

63. Wang, D.W.; Li, F.; Zhao, J.; Ren, W.; Chen, Z.G.; Tan, J.; Wu, Z.S.; Gentle, I.; Lu, G.Q.; Cheng, H.M. Fabrication of Graphene/polyaniline Composite Paper via in situ Anodic Electropolymerization for High-performance Flexible Electrode. ACS Nano 2009, 3, 1745-1752. [CrossRef]

64. Ali, A.A.S.; Farhat, A.; Mohamad, S.; Amira, A.; Bensaali, F.; Benammar, M.; Bermak, A. Embedded Platform for Gas Applications Using Hardware/Software Co-Design and RFID. IEEE Sens. J. 2018, 18, 4633-4642.

65. Ramos, A.; Clement, P.; Lazaro, A.; Llobet, E.; Girbau, D. Nitrogen Dioxide Wireless Sensor Based on Carbon Nanotubes and UWB RFID Technology. IEEE Antennas Wirel. Propag. Lett. 2015, 14, 1145-1148. [CrossRef]

66. Kim, S.; Cook, B.; Le, T.; Cooper, J.; Lee, H.; Lakafosis, V.; Vyas, R.; Moro, R.; Bozzi, M.; Georgiadis, A.; et al. Inkjet-printed Antennas, Sensors and Circuits on Paper Substrate. IET Microw. Antenna Propag. 2013, 7, 858-868. [CrossRef]

67. Rida, A.; Yang, L.; Vyas, R.; Tentzeris, M.M. Conductive Inkjet-printed Antennas on Flexible Low-cost Paper-based Substrates for RFID and WSN Applications. IEEE Antennas Propag. Mag. 2009, 51, 13-23. [CrossRef]

68. Bozzi, M.; Georgiadis, A.; Wu, K. Review of Substrate-integrated Waveguide Circuits and Antennas. IET Microw. Antennas Propag. 2011, 5, 909-920. [CrossRef]

69. Massoni, E.; Silvestri, L.; Alaimo, G.; Marconi, S.; Bozzi, M.; Perregrini, L.; Auricchio, F. 3-D Printed Substrate Integrated Slab Waveguide for Single-Mode Bandwidth Enhancement. IEEE Microw. Wirel. Compon. Lett. 2017, 27, 536-538. [CrossRef]

70. Rocco, G.M.; Bozzi, M.; Schreurs, D.; Perregrini, L.; Marconi, S.; Alaimo, G.; Auricchio, F. 3-D Printed Microfluidic Sensor in SIW Technology for Liquids' Characterization. IEEE Trans. Microw. Theory Tech. 2020, 68, 1175-1184. [CrossRef]

71. Moro, R.; Kim, S.; Bozzi, M.; Tentzeris, M.M. Inkjet-printed Paper-based Substrate-integrated Waveguide (SIW) Components and Antennas. Int. J. Microw. Wirel. Tech. 2013, 5, 197-204. [CrossRef]

72. Reinhold, I.; Thielen, M.; Voit, W.; Zapka, W.; Gotzen, R.; Bohlmann, H. Inkjet Printing of Electrical Vias. In Proceedings of the 18th European Microelectronics \& Packaging Conference, Brighton, UK, 2-15 September 2011.

73. Kawase, T.; Sirringhaus, H.; Friend, R.H.; Shimoda, T. Inkjet Printed Via-hole Interconnections and Resistors for All-polymer Transistor Circuits. Adv. Mater. 2001, 13, 1601-1605. [CrossRef]

74. Falat, T.; Felba, J.; Moscicki, A.; Borecki, J. Nano-silver Inkjet Printed Interconnections through the Microvias for Flexible Electronics. In Proceedings of the 11th IEEE International Conference on Nanotechnology, Portland, OR, USA, 15-18 August 2011.

75. Kim, S.; Shamim, A.; Georgiadis, A.; Aubert, H.; Tentzeris, M.M. Fabrication of Fully Inkjet-printed Vias and SIW Structures on Thick Polymer Substrates. IEEE Trans. Compon. Packag. Manuf. Technol. 2016, 6, 486-496. [CrossRef]

76. Available online: https://www.rogerscorp.cn/documents/606/acs/RT-duroid-5870-5880-Data-Sheet.pdf (accessed on 2 October 2020).

77. Khan, Y.; Thielens, A.; Muin, S.; Ting, J.; Baumbauer, C.; Arias, A.C. A New Frontier of Printed Electronics: Flexible Hybrid Electronics. Adv. Mater. 2019, 32, 1905279. [CrossRef]

78. Bhattacharjee, M.; Bandyopadhyay, D. Mechanisms of Humidity Sensing on a CdS Nanoparticle Coated Paper Sensor. Sens. Actuator A Phys. 2019, 285, 241-247. [CrossRef]

79. Li, Q.; Liu, H.; Zhang, S.; Zhang, D.; Liu, X.; He, Y.; Mi, L.; Zhang, J.; Liu, C.; Shen, C.; et al. Superhydrophobic Electrically Conductive Paper for Ultrasensitive Strain Sensor with Excellent Anticorrosion and Self-Cleaning Property. ACS Appl. Mater. Interfaces 2019, 11, 21904-21914. [CrossRef] [PubMed]

80. Maity, A.; Raychaudhuri, A.K.; Ghosh, B. High Sensitivity NH3 Gas Sensor with Electrical Readout Made on Paper with Perovskite Halide as Sensor Material. Sci. Rep. 2019, 9, 7777. [CrossRef] [PubMed]

81. Valentine, A.D.; Busbee, T.A.; Boley, J.W.; Raney, J.R.; Chortos, A.; Kotikian, A.; Berrigan, J.D.; Durstock, M.F.; Lewis, J.A. Hybrid 3D Printing of Soft Electronics. Adv. Mater. 2017, 29, 1703817. [CrossRef]

82. Kim, K.; Kim, B.; Lee, C.H. Printing Flexible and Hybrid Electronics for Human Skin and Eye-Interfaced Health Monitoring Systems. Adv. Mater. 2020, 32, 1902051. [CrossRef] 
83. Araki, T.; Uemura, T.; Yoshimoto, S.; Takemoto, A.; Noda, Y.; Izumi, S.; Sekitani, T. Wireless Monitoring Using a Stretchable and Transparent Sensor Sheet Containing Metal Nanowires. Adv. Mater. 2020, 32, 1902684. [CrossRef]

84. Ma, Y.; Zhang, Y.; Cai, S.; Han, Z.; Liu, X.; Wang, F.; Cao, Y.; Wang, Z.; Li, H.; Chen, Y.; et al. Flexible Hybrid Electronics for Digital Healthcare. Adv. Mater. 2020, 32, 1902062. [CrossRef]

85. Kim, S.; Georgiadis, A.; Collado, A.; Tentzeris, M.M. An Inkjet-printed Solar-powered Wireless Beacon on Paper for Identification and Wireless Power Transmission Applications. IEEE Trans. Microw. Theory Tech. 2012, 60, 4178-4186. [CrossRef]

86. Liu, W.; Huang, K.; Zhou, X.; Durrani, S. Next Generation Backscatter Communication: Systems, Techniques, and Applications. EURASIP J. Wirel. Commun. 2019, 69. [CrossRef]

87. Tao, Y.; Li, B.; Zhao, C.; Liang, Y.-C. Hardware-Efficient Signal Detection for Ambient Backscattering Communications. IEEE Commun. Lett. 2019, 23, 2196-2199. [CrossRef]

88. Deng, F.; He, Y.; Li, B.; Song, Y.; Wu, X. Design of a Slotted Chipless RFID Humidity Sensor Tag. Sens. Actuators $B$ Chem. 2018, 264, 255-262. [CrossRef]

89. Correia, R.; Boaventura, A.; Carvalho, N.B. Quadrature Amplitude Backscatter Modulator for Passive Wireless Sensors in IoT Applications. IEEE Trans. Microw. Theory Tech. 2017, 65, 1103-1110. [CrossRef]

90. Daskalakis, S.N.; Goussetis, G.; Assimonis, S.D.; Tentzeris, M.M.; Georgiadis, A. A uW Backscatter-Morse-Leaf Sensor for Low-Power Agricultural Wireless Sensor Networks. IEEE Sens. J. 2018, 18, 7889-7898. [CrossRef]

91. Kang, J.S.; Kim, H.S.; Ryu, J.; Hahn, H.T.; Jang, S.; Joung, J.W. Inkjet Printed Electronics using Copper Nanoparticle Ink. J. Mater. Sci. Mater. Electron. 2010, 21, 1213-1220. [CrossRef]

92. Park, S.-H.; Chung, W.-H.; Kim, H.-S. Temperature Changes of Copper Nanoparticle Ink During Flash Light Sintering. J. Mater. Process. Technol. 2014, 214, 2730-2738. [CrossRef]

93. Kim, S.; Jeong, S.; Bito, J.; Georgiadis, A.; Tentzeris, M.M. A Flexible RF Energy Harvester using a Hybrid Printing Technology for 'Stand-alone' Wireless Sensor Platforms. Flex. Print. Electron. 2018, 3, 015004. [CrossRef]

94. Sievenpiper, D.; Zhang, L.; Broas, R.F.J.; Alexopolous, N.G.; Yablonovitch, E. High-Impedance Electromagnetic Surfaces with a Forbidden Frequency Band. IEEE Trans. Microw. Theory Tech. 1999, 47, 2059-2074. [CrossRef]

95. Cook, B.S.; Shamim, A. Utilizing wideband AMC Structures for High Gain Inkjet-printed Antennas on Lossy Paper Substrate. IEEE Antennas Wirel. Propag. Lett. 2013, 12, 76-79. [CrossRef]

96. Zhu, S.; Langley, R. Dual-band Wearable Textile Antenna on an EBG Substrate. IEEE Trans. Antennas Propag. 2009, 57, 926-934. [CrossRef]

97. Cooper, J.R.; Kim, S.; Tentzeris, M.M. A Novel Polarization-independent, Free-space, Microwave Beam Splitter utilizing an Inkjet-printed, 2-D Array Frequency Selective Surface. IEEE Antennas Wirel. Propag. Lett. 2012, 11, 686-688. [CrossRef]

98. Assimonis, S.D.; Fusco, V. Polarization Insensitive, Wide-Angle, Ultra-wideband, Flexible, Resistively Loaded, Electromagnetic Metamaterial Absorber using Conventional InkjetPrinting Technology. Sci. Rep. 2019, 9, 12334. [CrossRef] [PubMed]

99. Jiang, W.; Yan, L.; Ma, H.; Fan, Y.; Wang, J.; Feng, M.; Qu, S. Electromagnetic Wave Absorption and Compressive Behavior of a Three-dimensional Metamaterial Absorber Based on 3D Printed Honeycomb. Sci. Rep. 2018, 8, 4817. [CrossRef] [PubMed]

100. Kim, S.; Ren, Y.-J.; Lee, H.; Rida, A.; Nikolaou, S.; Tentzeris, M.M. Monopole antenna with inkjet-printed EBG array on paper substrate for wearable applications. IEEE Antennas Wirel. Propag. Lett. 2012, 11, 663-666. [CrossRef]

101. Basar, E.; Renzo, M.D.; Rosny, J.D.; Debbah, M.; Alouini, M.-S.; Zhang, R. Wireless Communications Through Reconfigurable Intelligent Surfaces. IEEE Access 2019, 7, 116753-116773. [CrossRef]

102. Palma, L.D.; Clemente, A.; Dussopt, L.; Sauleau, R.; Potier, P.; Pouliguen, P. Circularly-Polarized Reconfigurable Transmitarray in Ka-Band with Beam Scanning and Polarization Switching Capabilities. IEEE Trans. Antennas Propag. 2017, 65, 529-540. [CrossRef]

103. Dai, L.; Wang, B.; Wang, M.; Yang, X.; Tan, J.; Bi, S.; Xu, S.; Yang, F.; Chen, Z.; Renzo, M.D.; et al. Reconfigurable Intelligent Surface-Based Wireless Communications: Antenna Design, Prototyping, and Experimental Results. IEEE Access 2020, 8, 45913-45923. [CrossRef] 
104. Özdogan, Ö.; Björnson, E.; Larsson, E.G. Intelligent Reflecting Surfaces: Physics, Propagation, and Pathloss Modeling. IEEE Wirel. Commun. Lett. 2020, 9, 581-585. [CrossRef]

105. Available online: https://kb.ettus.com/N200/N210 (accessed on 2 October 2020).

106. Lee, H.; Kim, S.; Donno, D.D.; Tentzeris, M.M. A Novel “Universal” Inkjet-printed EBG-backed Flexible RFID for Rugged on-body and Metal Mounted Applications. In Proceedings of the IEEE/MTT-S International Microwave Symposium Digest, Montreal, QC, Canada, 17-22 June 2012.

(c) (4)

(C) 2020 by the author. Licensee MDPI, Basel, Switzerland. This article is an open access article distributed under the terms and conditions of the Creative Commons Attribution (CC BY) license (http://creativecommons.org/licenses/by/4.0/). 